\title{
LA DIVERSIDAD POLÍTICA VA A MEJORAR LA CIENCIA DE LA PSICOLOGÍA SOCIAL*
}

\author{
José L. Duarte \\ Universidad Estatal de Arizona \\ jlduarte@asu.edu
}

Charlotta Stern

Universidad de Estocolmo

lotta.stern@sofi.su.se

\section{Lee Jussim}

Universidad de Rutgers

jussim@rci.rutgers.edu

\author{
Jarret T. Crawford \\ The College of New Jersey \\ crawford@tcnj.edu
}

\section{Jonathan Haidt}

Universidad de Nueva York

haidt@nyu.edu

\author{
Philip E. Tetlock \\ Universidad de Pensilvania \\ tetlock@wharton.upenn.edu.
}

Resumen: Los psicólogos han demostrado el valor de la diversidad —en especial, la diversidad de puntos de vista - para potenciar la creatividad, la capacidad de descubrimiento y la solución de problemas. Pero un tipo clave de diversidad sigue ausente en la psicología académica, en general, y en la psicología social, en particular: la diversidad política. Este artículo revisa la evidencia disponible y halla elementos que respaldan cuatro afirmaciones: 1) La psicología

\footnotetext{
* Publicado originalmente en Behavioral and Brain Sciences 38 (2015). Traducimos aquí, con la debida autorización, el artículo original y una selección de los numerosos comentarios críticos que acompañaron su publicación en dicha revista. La traducción fue realizada por Cristóbal Santa Cruz para Estudios Públicos.

Todos los autores contribuyeron de manera sustancial y son nombrados en orden inverso según su antigüedad académica. Ellos agradecen a Bill von Hippel, Michael Huemer, Jon Krosnick, Greg Mitchell, Richard Nisbett y Bobbie Spellman por sus comentarios a versiones preliminares de este artículo, si bien ello no implica necesariamente que suscriban las opiniones expresadas en este artículo.
} 
académica solía tener una considerable diversidad política, pero la ha perdido casi por completo en los últimos 50 años. 2) Esta falta de diversidad política puede socavar la validez de la psicología social como ciencia, al introducir valores liberales ${ }^{1}$ en las interrogantes y metodologías de investigación, alejar a los investigadores de temas de investigación relevantes, pero políticamente incómodos y generar conclusiones que describen erróneamente tanto a los liberales como a los conservadores. 3) Una mayor diversidad política mejoraría la ciencia de la psicología social, reduciendo el impacto de los mecanismos de sesgo, tales como el sesgo de confirmación, y empoderando a las minorías disidentes para que mejoren la calidad de la reflexión de las mayorías. 4) La baja representación de no liberales en la psicología social muy probablemente se deba a una combinación de autoselección, ambiente hostil y discriminación. El artículo concluye con una serie de recomendaciones para lograr una mayor diversidad política en la psicología social.

PALABRAS Claves: sesgo académico, diversidad académica, sesgo de confirmación, discriminación, ciencia abierta, psicología política, psicología social.

\section{POLITICAL DIVERSITY WILL IMPROVE SOCIAL PSYCHOLOGICAL SCIENCE}

ABSTRACT: Psychologists have demonstrated the value of diversity - particularly diversity of viewpoints-for enhancing creativity, discovery, and problem solving. But one key type of viewpoint diversity is lacking in academic psychology in general and social psychology in particular: political diversity. This article reviews the available evidence and finds support for four claims: (1) Academic psychology once had considerable political diversity, but has lost nearly all of it in the last 50 years. (2) This lack of political diversity can undermine the validity of social psychological science via mechanisms such as the embedding of liberal values into research questions and methods, steering researchers away from important but politically unpalatable research topics, and producing conclusions that mischaracterize liberals and conservatives alike. (3) Increased political diversity would improve social psychological science by reducing the impact of bias mechanisms such as confirmation bias, and by empowering dissenting minorities to improve the quality of the majority's thinking. (4)

${ }^{1}$ Cuando se use la expresión "liberal" o "valores liberales", se hará en el sentido estadounidense del término, es decir, aludiendo a la tradición socialdemócrata norteamericana antes que a la tradición europea del liberalismo clásico (N.del E.). 
The underrepresentation of non-liberals in social psychology is most likely due to a combination of self-selection, hostile climate, and discrimination. We close with recommendations for increasing political diversity in social psychology.

KeYwords: academic bias, academic diversity, confirmation bias, discrimination, open science, political psychology, social psychology.

Aquel que sólo conoce su propio enfoque del caso, poco sabe sobre éste. —John Stuart Mill, On Liberty ([1859] 1989, 38)

\section{INTRODUCCIÓN}

D urante los últimos años, la psicología social ha debido enfrentar una serie de desafíos relacionados con la validez de sus investigaciones, entre ellos, algunos bullados errores de replicación, casos de fraude, artículos sobre prácticas de investigación cuestionables y sobreestimación del tamaño de los efectos (John et al. 2012; Simmons et al. 2011). A modo de respuesta, la Society for Personality and Social Psychology (SPSP) convocó a una mesa de trabajo para analizar los temas de publicación y prácticas de investigación, la que elaboró un conjunto de recomendaciones estadísticas, metodológicas y prácticas, a fin de limitar las faltas de integridad y robustecer la validez de la psicología social (Funder et al. 2014, 18). En este artículo, sugerimos que una de las razones no consideradas que explican dicho fracaso es la falta de diversidad política. Revisamos evidencia que sugiere que un mayor nivel de diversidad política y de disentimiento mejoraría la confiabilidad y validez de la psicología social.

No somos los primeros en esgrimir este argumento. Tetlock (1994) identificó las diferentes formas en que los valores morales y políticos llevaban a conclusiones injustificadas en materia de disuasión nuclear y de prejuicios, y Redding (2001) mostró que la falta de diversidad política en los diferentes ámbitos de la psicología atenta contra la validez de las conclusiones de esta ciencia. Por desgracia, estas consideraciones 
han sido en gran parte ignoradas. Como mostraremos, los motivos de preocupación cobran hoy mayor fuerza que al momento en que Tetlock y Redding publicaron sus críticas. En este artículo, hacemos cinco contribuciones a la literatura científica, cada una de las cuales corresponde a una sección del artículo. La sección 2 ilustra cómo, si bien la psicología en un momento se caracterizó por una considerable diversidad política, durante las cuatro últimas décadas exhibe una marcada tendencia hacia la homogeneidad política. En la sección 3 se identifican tres factores de riesgo que apuntan a cómo la falta de diversidad política puede atentar contra la validez de la investigación científica. En base a hallazgos de la psicología organizacional, en la sección 4 demostramos que una mayor diversidad política puede contribuir a mejorar la ciencia de la psicología social. En la sección 5 se examinan las posibles fuentes de homogeneidad política en la psicología social actual, entre ellas, las diferencias entre los liberales y no liberales en cuanto a habilidades e intereses, la hostilidad hacia los puntos de vista no liberales y la discriminación en contra de los no liberales. En la sección 6, se entregan algunas recomendaciones para promover la diversidad política entre los psicólogos sociales y reducir los efectos nocivos de la homogeneidad política en la investigación.

Antes de comenzar, es necesario hacer algunas aclaraciones sobre la terminología empleada en este artículo. En primer lugar, utilizamos el término "psicología social" para incluir también a la psicología de la personalidad, ya que ambos campos están estrechamente vinculados y porque resulta largo y tedioso referirse continuamente a la "ciencia de la psicología social y de la personalidad". Nos focalizamos en la psicología social porque es el campo de la psicología que se aboca en forma más directa al análisis de temas ideológicamente controvertidos y, por ende, es el que más exige una diversidad política en su mirada. Segundo, nos centramos en los conservadores ${ }^{2}$ como grupo subrepresentado, porque los datos sobre la prevalencia en psicología de diferentes grupos ideológicos permiten un mejor contraste entre liberales y conservadores, y porque en este ámbito la desviación en cuanto a la proporción de liberales y conservadores en la población estadounidense es muy

${ }^{2}$ Tal como en el uso de la palabra liberal, el término "conservador", para fines de este artículo, refiere a la tradición norteamericana de derecha (N. del E.). 
alta. No obstante, argumentamos que el campo requiere un mayor número de no liberales, independientemente de cómo dichas personas se identifiquen a sí mismas (esto es, como libertarios o moderados). En tercer lugar, es importante reconocer que el conservadurismo no es monolítico; de hecho, es probable que exista una mayor diversidad de afiliaciones políticas entre quienes se identifican como conservadores que entre los liberales (Feldman y Johnston 2014; Klein y Stern 2005; Stenner 2009). Cuarto, para satisfacer la curiosidad del lector, mencionaremos que entre quienes colaboraron en este artículo hay un liberal, una persona de centro, dos libertarios, una persona cuyas idea políticas no encuadran dentro de la clasificación derecha/izquierda, y un opositor al neopositivismo que se declara a favor de una política "no preguntes, no digas", en la que la erudición debe ser juzgada de acuerdo a sus propios méritos. Ninguno de nosotros se identifica como conservador o republicano.

Es necesario agregar un último comentario: la falta de diversidad política no constituye una amenaza para la validez de los estudios específicos en muchas - y tal vez la mayoría — de las áreas de investigación de la psicología social. La falta de diversidad genera problemas para el proceso científico, principalmente en temas relacionados con las inquietudes políticas de la izquierda, como la raza, el género, los estereotipos, la ecología, el poder y la desigualdad, así como en áreas en que se estudia a los conservadores, como la psicología moral y política. Y no estamos sugiriendo que en dichas áreas la mayoría de las investigaciones sean defectuosas o erróneas. Más bien, argumentamos que al abordar temas con carga política, puede que los esfuerzos conjuntos de los investigadores no logren converger en una verdad cuando hay pocos o ningún investigador liberal capaz de plantear interrogantes e hipótesis alternativas. No es nuestra intención en este artículo desmantelar la psicología social, campo con una larga trayectoria de investigaciones que han sido cruciales para comprender y mejorar la condición humana (véanse ejemplos en Zimbardo 2004). Nos sentimos orgullosos de ser psicólogos sociales y creemos que nuestro campo puede adoptar - y efectivamente lo hará- algunos métodos relativamente sencillos para utilizar la diversidad en pos de su propio perfeccionamiento como ciencia. 


\section{LA SICOLOGÍA ES POLÍTICAMENTE MENOS DIVERSA QUE NUNCA}

Existen muchos ámbitos académicos en que las encuestas indican que las personas que se definen como conservadoras son casi tan numerosas como las se definen como liberales; por lo general, éstas provienen del ámbito de los negocios, la informática, la ingeniería, la ciencia de la salud y las áreas técnico-vocacionales (Gross y Simmons 2007; Zipp y Fenwick 2006). ${ }^{3}$ Sin embargo, en las ciencias sociales y las humanidades existe un mayor desequilibrio. Por ejemplo, las encuestas recientes arrojan que el 58-66 por ciento de los profesores de ciencias sociales en los Estados Unidos se identifican como liberales, en tanto que sólo el 5-8 por ciento se identifican como conservadores, y que quienes se definen como demócratas superan a los republicanos en una proporción de al menos 8 a 1 (Gross y Simmons 2007; Klein y Stern 2009; Rothman y Lichter 2008). En las humanidades nos encontramos con una situación similar, ya que las encuestas señalan que el 52-77 por ciento de los profesores de humanidades se identifican como liberales y únicamente el 4-8 por ciento como conservadores, y que quienes se autodenominan demócratas superan a los republicanos en una proporción de al menos 5 a 1 (Gross y Simmons 2007; Rothman y Lichter 2008). En psicología, el desequilibrio es ligeramente más pronunciado: el 84 por ciento se identifican como liberales, mientras que sólo el 8 por ciento, como conservadores. Esto se traduce en una proporción de 10,5 a 1. En los Estados Unidos, la proporción entre liberales y conservadores es de aproximadamente 1 a 2 (encuesta Gallup 2010; véase Saad 2010).

¿Se ha inclinado siempre la psicología social en forma tan pronunciada hacia la izquierda? La información disponible es imperfecta, ya que los únicos datos que se remontan a varios decenios se centran en la identificación con un partido (demócrata versus republicano; McClintock et al. 1965) y no en una identidad ideológica. Antes de los años ochenta, la afiliación a un partido no se correlacionaba con la dimensión derecha-izquierda en forma tan marcada como hoy (Barber y McCarty 2013). Existía una minoría importante de republicanos liberales y de demócratas conservadores. No obstante, desde inicios

\footnotetext{
${ }^{3}$ Ambos estudios incluyen universidades comunitarias en sus análisis.
} 
del siglo veinte, el partido demócrata se ha transformado en el partido de izquierda y el partido republicano, en el de derecha (Levendusky 2009). En el gráfico 1, ilustramos todos los datos disponibles acerca de la identidad política de los psicólogos de las universidades estadounidenses, incluida su identificación con un partido (diamantes) como su identificación con los liberales o conservadores (círculos). Ambos conjuntos de datos arrojan un marcado proceso de izquierdización. En

\section{Gráfico 1. IDENTIDAD POLÍTICA DE LOS PSICÓLOGOS DE LAS UNIVERSIDADES ESTADOUNIDENSES}

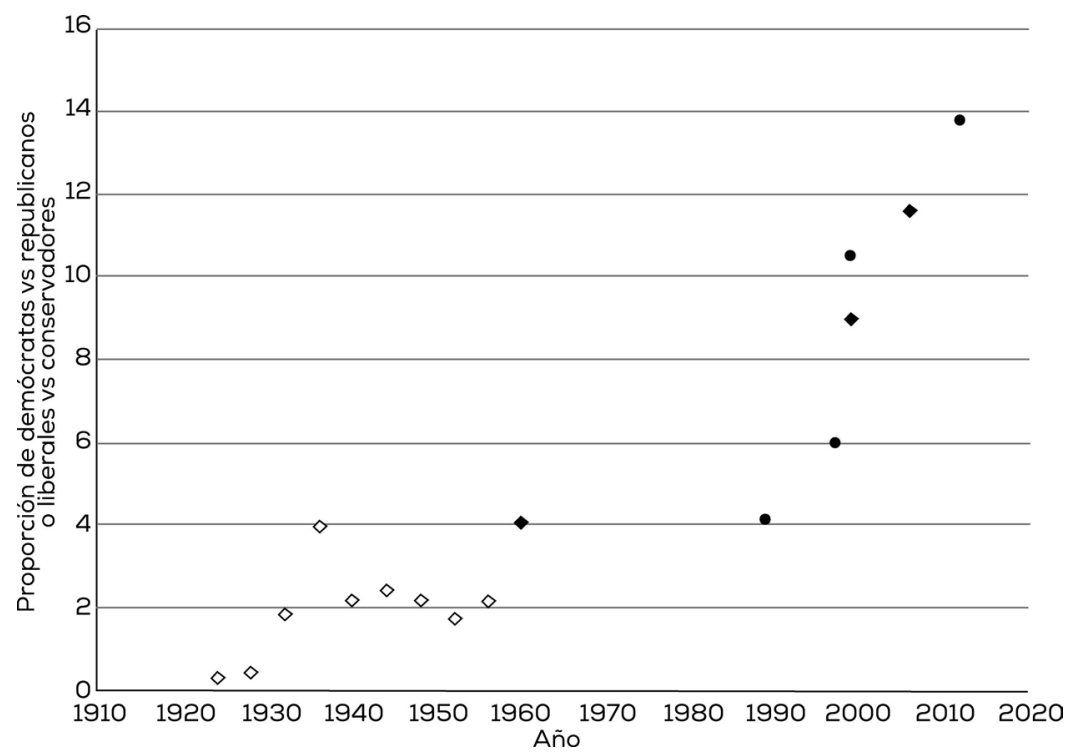

Con el correr de los años, la afiliación política y las simpatías ideológicas de los psicólogos académicos se han desplazado hacia la izquierda. Los circulos muestran la proporción de sujetos que se definen como liberales versus quienes se definen como conservadores. Los diamantes muestran la proporción entre las preferencias declaradas por un partido o la votación (demócratas versus republicanos). Los datos para los años 1924-1960 aparecen en McClintock et al. (1965). Los diamantes abiertos representan los candidatos por los cuales los participantes recuerdan haber votado; los diamantes negros representan la identificación con un partido declarada por los participantes al momento de la encuesta. Los datos de 1999 son de Rothman et al. (2005). Los datos de 2006 de Gross y Simmons (2007). El círculo de la derecha es de Inbar y Lammers (2012) y representa la proporción de psicólogos sociales que se definen a si mismos como liberales/conservadores. 
las elecciones presidenciales de 1920, los profesores de psicología eran igualmente propensos a declarar que habían votado por los republicanos que por los demócratas. Desde los años treinta hasta 1960, era más probable que declararan haber votado por los demócratas, pero importantes minorías votaron por Wilkie, Eisenhower, y Nixon (en 1960). Sin embargo, en 2006, la proporción entre demócratas y republicanos había ascendido a más de 11:1 (Gross y Simmons 2007; Rothman y Lichter 2008).

¿Existe menos diversidad política en la psicología social que en la psicología académica en su conjunto? Nunca se ha realizado una encuesta exhaustiva y representativa de las posturas políticas de los psicólogos sociales, pero contamos con dos fuentes de evidencia, aunque imperfectas. Una de las instancias más importantes en la que se reúnen los psicólogos sociales es el simposio presidencial de la reunión anual de la SPSP. En la reunión del año 2011, en San Antonio, Texas, Jonathan Haidt le pidió a los casi mil asistentes que se identificaran políticamente levantando la mano. Contó el número exacto de manos alzadas a favor de la opción "conservador o de derecha" (3 manos), "moderados o de centro" (20 manos), y "libertarios" (12 manos). En relación a la opción "liberal de izquierda" le fue imposible contar, pero hizo una estimación de que aproximadamente el 80 por ciento de la sala alzó la mano (es decir, en términos generales, 800 liberales). La proporción resultante entre liberales y conservadores de 267:1 es, sin duda, una sobreestimación. En esta encuesta no anónima, es probable que muchos conservadores se mostraran renuentes a levantar la mano. Pero si esto fue lo que ocurrió y los conservadores se mostraron en su gran mayoría reacios a identificarse como tales, ello ilustra el problema que estamos planteando.

La otra prueba de que disponemos proviene de una encuesta anónima realizada en internet por Inbar y Lammers (2012), quienes se propusieron someter a prueba la afirmación de Haidt de que prácticamente no había conservadores en el ámbito de la psicología social. Enviaron una invitación por correo electrónico a la lista completa de asistentes a la reunión de la SPSP, a la cual respondieron $292^{4}$ individuos. Inbar

${ }^{4}$ Inbar y Lammers (2012) realizaron dos encuestas valiéndose de la misma lista de correo. La primera fue más breve y obtuvo 508 respuestas. Dicha encuesta no investigó acerca de una identidad política global; sus preguntas apuntaban a la identificación personal respecto de temas económicos, sociales y de política exte- 
y Lammers hallaron que el 85 por ciento de las personas que completaron la encuesta se declararon liberales, el 9 por ciento, moderados, y tan sólo el 6 por ciento, conservadores ${ }^{5}$ (una proporción de 14:1). Adicionalmente, la tendencia hacia la homogeneidad política parece estar acentuándose: si bien el 10 por ciento de los profesores que llenaron la encuesta se identificaron como conservadores, solamente el 2 por ciento de los estudiantes de postgrado y postdoctorado se autodenominaron como tales (Inbar 2013, comunicación personal). Este patrón es consistente con las tendencias más amplias en la psicología, ilustradas en el gráfico 1: el campo de la psicología se inclina cada vez más hacia la izquierda, la proporción entre liberales y conservadores es ahora mayor a 10:1 y casi no hay estudiantes conservadores entre quienes están en proceso de formación.

\section{TRES FORMAS EN QUE LA FALTA DE DIVERSIDAD PERJUDICA A LA PSICOLOGÍA SOCIAL}

Si no se interviene a tiempo, un campo académico puede llegar a transformarse en una comunidad moral cohesionada, que crea una realidad compartida (Hardin y Higgins 1996) y que posteriormente ciega a sus miembros frente a hipótesis moral o ideológicamente indeseables y

rior. De estos tres temas, pensamos que ser un conservador social es el que representa el mayor tabú; sólo el 3,9 por ciento de los entrevistados señalaron que eran conservadores en temas sociales. Cabe destacar que Inbar y Lammers obtuvieron un mayor número de personas dispuestas a declarar que eran conservadores en temas sociales (17,9 por ciento) y de política exterior (10,3 por ciento), pero pensamos que es la identidad global - la voluntad de afirmar "soy un conservador" versus "soy un liberal" - la mejor forma de plasmar una diversidad política. Por ello, nos centramos en su segundo estudio que incluye también un conjunto más amplio de mediciones relacionadas con la discriminación política.

${ }^{5}$ Entregamos este dato adicional: en su presentación de 2011 en la Society for Personality and Social Psychology, Haidt señaló que sólo pudo identificar a un psicólogo social conservador que tuviera algún grado de reconocimiento público como tal en toda la disciplina: Clark McCauley. Tres años después de esa charla, ningún otro psicólogo social conservador se ha manifestado públicamente o ha sido identificado como tal, como contraejemplo a la afirmación de Haidt de que la disciplina carece de diversidad política. Los cinco autores de este artículo conocen sólo un psicólogo social conservador adicional, pero éste ha solicitado que su nombre sea mantenido bajo reserva. Si la psicología social tiene en la práctica más diversidad política que lo que afirmamos en este artículo, nadie parece saber dónde encontrarla. 
frente a problemas científicos relevantes aún sin resolver (Haidt 2012). El sociólogo Christian Smith (2003) ha estudiado a las comunidades morales de este tipo en el ámbito académico y ha identificado un conjunto de narrativas morales que vinculan las concepciones históricas de los investigadores con su forma de concebir la investigación. Smith describe el ámbito de la sociología con inclinaciones de izquierda como una esfera que comparte lo que él denomina la "narrativa del progreso liberal":

Hubo un momento en el que una gran mayoría de personas padecieron grandes sufrimientos en sociedades e instituciones inequitativas, poco saludables, represivas y opresivas. Estas sociedades eran reprobables debido a sus condiciones de profunda desigualdad, explotación y tradicionalismo irracional... Pero las nobles aspiraciones humanas de autonomía, igualdad y prosperidad se enfrentaron valerosamente contra las fuerzas de la miseria y la opresión y lograron constituir sociedades modernas, liberales, democráticas... de bienestar. Aun cuando las condiciones sociales de la modernidad tienen el potencial de maximizar la libertad individual y el goce de todos sus miembros, queda mucho por hacer para desmantelar los poderosos vestigios de desigualdad, explotación y represión. Esta lucha en pos de una buena sociedad en la que los individuos sean iguales y libres para alcanzar una felicidad definida en sus propios términos es la única misión a la que vale la pena dedicarse. (Smith 2003, 82)

Aunque Smith escribió esta narrativa pensando en la sociología, también resulta plausible para la psicología social, un campo que ha producido abundantes investigaciones sobre el racismo, el sexismo, los estereotipos y las nefastas consecuencias del poder y la obediencia a la autoridad. Dada la homogeneidad política existente que evidenciamos en la sección 2 de este artículo, la psicología social corre el riesgo de transformarse en una comunidad moral cohesionada. ¿Es posible que una narrativa moral-histórica compartida en un ámbito políticamente homogéneo debilite los procesos de autocorrección de los que depende una buena ciencia? Así lo creemos y presentamos tres riesgos - tres formas en que la homogeneidad política puede constituir una amenaza para la validez de la psicología social - y ejemplos tomados de la literatura existente que ilustran cada uno de ellos. 


\subsection{Riesgo 1: Los valores y supuestos liberales pueden hacerse subyacentes a la teoría y el método}

Los valores políticos pueden verse contenidos en forma subyacente en las preguntas de la investigación haciendo que algunos constructos sean inobservables o inmedibles y, por lo tanto, invalidando los intentos de someter a prueba una hipótesis (Sniderman y Tetlock 1986; Tetlock 1994; Tetlock y Mitchell 1993). Los valores están encapsulados cuando las declaraciones de valor y las afirmaciones ideológicas son tratadas erróneamente como una verdad objetiva y la desviación observada de dicha verdad es concebida como un error.

3.1.1. Ejemplo 1: Negación de las realidades ambientales. Feygina et al. (2010) trataron de explicar la "negación de las realidades ambientales" mediante la teoría de la justificación sistémica (Jost y Banaji 1994). Al operacionalizar dicha negación, los autores evaluaron los cuatro constructos que presentamos a continuación, con ejemplos ilustrativos entre paréntesis:

Constructo 1: Negación de la posibilidad de una crisis ecológica. ("Si las cosas siguen su curso, pronto experimentaremos una gran catástrofe ambiental", con puntaje inverso.)

Constructo 2: Negación de los límites del crecimiento. ("La Tierra cuenta con suficientes recursos naturales, sólo se requiere aprender a desarrollarlos.")

Constructo 3: Negación de la necesidad de someterse a las limitaciones impuestas por la naturaleza. ("En algún momento la humanidad conocerá cabalmente el funcionamiento de la naturaleza y podrá controlarla.")

Constructo 4: Negación del peligro de alterar el equilibrio de la naturaleza. ("El equilibrio de la naturaleza es lo suficientemente sólido como para hacer frente a los impactos de las naciones modernas industrializadas.")

El principal problema con esta investigación es que desestima a quienes están en desacuerdo con los valores y consignas ambientalistas y los conceptúa como en "estado de negación". De hecho, los artículos que Feygina et al. (2010) citaron para respaldar la "negación" de deter- 
minados temas nunca utilizaron los términos "negar" o "negación" para describir dichos indicadores. Clark et al. (2003) se refirieron a estos ítems como una evaluación de "actitudes" y Dunlap et al. (2000) los caracterizaron como ejemplos de "creencias primarias" (439) sobre el medio ambiente.

El término "negación" (denial) implica que: 1) la afirmación que se niega constituye una "realidad", es decir, un hecho descriptivo, y 2) cualquiera que no comparta el carácter pro ambientalista de dichas afirmaciones incurre en una actitud psicológica de negación. A continuación describimos por qué ambas aseveraciones son falsas y por qué los indicadores, si bien pueden ser adecuados para evaluar actitudes o creencias primarias, no permiten medir la negación.

El constructo 1 se refiere a una "posibilidad"; por lo tanto, la negación equivaldría a la creencia en la imposibilidad de una crisis ecológica. Sin embargo, esto no se evaluó y el indicador que supuestamente permitía evaluar el constructo no se refiere a ningún hecho descriptivo. Sin una definición de "pronto" o "gran" o "crisis" es imposible que se trate de un hecho. Al no tratarse de una afirmación sobre un hecho real, estar en desacuerdo con ella en ningún caso puede representar una negación.

Los problemas con el constructo 2 y su medición son de índole similar. La negación de los límites del crecimiento se podría medir si estamos de acuerdo con una afirmación alternativa, como, por ejemplo: "Los recursos naturales con que cuenta la Tierra son infinitos". El estar de acuerdo con dicha afirmación podría considerarse como una forma de negación de los límites del crecimiento. Sin embargo, esto no se evaluó. En ausencia de una definición de "suficientes", no queda claro cómo se podría refutar o confirmar este ítem. Si no puede ser refutado o confirmado, no puede tratarse de un hecho descriptivo. Si no es un hecho, se puede estar de acuerdo o en desacuerdo, pero no hay "negación". Incluso estar muy de acuerdo con esta afirmación no necesariamente implica que existan límites al crecimiento. "Suficientes" no implica "ilimitados". Más aún, la supuesta realidad que se está negando ha sido objeto de fuertes controversias entre los estudiosos del tema y afirmar que, dado el ingenio humano, los recursos de la Tierra son suficientemente abundantes para satisfacer las necesidades de la humanidad fue una estrategia ganadora en una famosa apuesta científica (Sabin 2013). 
El constructo 3 es una afirmación categórica que sostiene la necesidad de someterse a las restricciones impuestas por la naturaleza. Nuevamente, las "restricciones impuestas por la naturaleza" es un término vago e indefinido. Además, el constructo no es un hecho descriptivo, sino una prescripción filosófico-ideológica y el ítem es una profecía, lo que no puede considerarse como un hecho. Por lo tanto, este constructo puede dar cuenta de una actitud hacia el medio ambiente, pero no da cuenta de ninguna negación. Sería igualmente injustificado calificar a quienes están en desacuerdo con el ítem como personas que niegan la creatividad humana, la innovación y la inteligencia.

El constructo 4 es igualmente problemático. "Equilibrio de la naturaleza" es otro término impreciso y el ítem que lo mide es una predicción vaga. Uno puede estar de acuerdo o en desacuerdo con el ítem. Y puede que dichas diferencias sean psicológicamente importantes; sin embargo, el desacuerdo no equivale a una negación.

Si efectivamente algunas personas niegan las realidades ambientales, sería interesante y potencialmente abordable —en términos científicos- estudiar las razones que explican dicha negación. Por ejemplo, se podría evaluar "la negación ambiental" mostrándoles a las personas un video con secuencias tomadas a lo largo de los años que dan cuenta de cómo se ha elevado el nivel del mar alrededor de una isla y luego preguntarles si el nivel del mar se está elevando. Existiría un caso prima facie para calificar a quienes respondieron con un "no" a dicha pregunta como personas que "niegan las realidades ambientales". Sin embargo, Feygina et al. (2010) no realizaron estudios de este tipo. Simplemente midieron el respaldo a las creencias y valores ambientales de base, determinaron que los niveles bajos de respaldo constituían una negación y realizaron una regresión de los puntajes de justificación y otras medidas (en un tercer estudio experimental no evaluaron esta negación). Ninguna de las mediciones de Feygina et al. se refiere a realidades ambientales. Por lo tanto, los estudios no lograron producir evidencia científica sobre la negación de las realidades ambientales.

Las consignas y los valores filosóficos ambientalistas imprecisos se transforman indebidamente en verdades científicas, aunque nunca habrá un dato que nos señale que los seres humanos deben "someterse a las restricciones impuestas por la naturaleza". No se trata sólo de que las personas tengan actitudes disímiles en relación al medio ambiente; 
el problema es asumir que determinadas actitudes son correctas y que quienes están en desacuerdo tienen una actitud negacionista. La transformación de una ideología política ampliamente compartida en una "realidad" y el concomitante tratamiento del disenso como negación reflejan el poder que tienen los valores subyacentes para distorsionar la ciencia dentro de una comunidad moralmente cohesionada.

3.1.2. Ejemplo 2: Ideología y conducta poco ética. Son Hing et al. (2007) hallaron que: 1) era más probable que los sujetos con altas puntuaciones en la escala de orientación a la dominancia social (social dominance orientation, SDO) adoptaran decisiones poco éticas; 2) existían mayores probabilidades de que los sujetos con puntuaciones altas en el autoritarismo de derecha (right-wing authoritarianism, RWA) estuvieran de acuerdo con las decisiones poco éticas de los líderes; y 3) las díadas en que los líderes tenían altas puntuaciones en la escala SDO y los seguidores con altas puntuaciones en RWA tomaban más decisiones poco éticas que las díadas con diferentes ordenamientos (por ejemplo, aquellas con un bajo SDO y RWA).

Pero considérense las decisiones que los autores definieron como poco éticas: no tomar partido formalmente con una colega del sexo femenino en su acusación de ser víctima de acoso sexual por parte de un subordinado (habiendo poca información respecto del caso), y un trabajador que antepone el bienestar de su empresa a daños inespecíficos al medio ambiente atribuidos a las operaciones de la compañía. Los valores liberales del feminismo y el ambientalismo eran tan inherentes a la operacionalización de la ética que se esperaba que los participantes respaldaran dichos valores en viñetas que carecían de la información necesaria para emitir un juicio con conocimiento de causa.

\subsubsection{Cómo reconocer y evitar los sesgos relacionados con los} valores subyacentes. La existencia de ciertas palabras que implican motivaciones perniciosas (por ejemplo: negar, legitimar, racionalizar, justificar, defender, trivializar) puede ser particularmente indicativo de que la investigación está impregnada de valores subyacentes. El empleo de estos términos implica, por ejemplo, que el punto de vista que se niega es objetivamente válido y que el punto de vista que se "justifica" es objetivamente inválido. En algunos casos, esto es científicamente sos- 
tenible, como, por ejemplo, cuando un investigador está interesado en negar un hecho objetivo. La racionalización se puede demostrar empíricamente, pero, para hacerlo, no basta con declarar que ciertas creencias son racionalizaciones, como en el caso de Napier y Jost (2008), en que el respaldo a la efectividad del trabajo arduo — en un ítem - fue etiquetado como racionalización de la desigualdad.

Las pruebas con hipótesis de contraste (turnabout tests) a menudo constituyen una herramienta sencilla para identificar y evitar el sesgo de los valores subyacentes (Tetlock 1994). Imaginemos un ámbito hipotético de la psicología social en que los puntos de vista políticos de los conservadores fueran tratados como hechos científicos y el desacuerdo con los puntos de vista conservadores fuera considerado como negación o error. En dicho ámbito, los eruditos podrían publicar estudios sobre "la negación de los beneficios del libre mercado" o "la negación de los beneficios de contar con un ejército poderoso" o "la negación de los beneficios de asistir a misa". También podrían publicar estudios en que se demuestra que las personas con un bajo RWA y SDO (es decir, los liberales) son menos éticos porque son más propensos a no respetar la autoridad, a desconocer la propiedad privada y a limitar las opciones individuales en el mercado. Cuando cualquier tipo de valor ideológico queda encapsulado en las mediciones, ello representa un peligro para la ciencia. Más adelante en este artículo, revisaremos evidencia que sugiere que es mucho más probable que ello ocurra y que no sea impugnado por quienes están en desacuerdo en un ámbito políticamente homogéneo.

\subsection{Riesgo 2: Es posible que los investigadores se focalicen en temas que validan la narrativa liberal sobre el progreso y que eviten los temas que rebaten dicha narrativa}

Desde los tiempos de la Ilustración, los científicos han concebido su labor como una forma de poner luz ahí donde hay oscuridad. La metáfora es adecuada, pero en un ámbito políticamente homogéneo, un número de científicos — no menor, por desgracia — apunta sus focos hacia aquellas zonas ideológicas que les parecen relevantes. Cuando esto ocurre, muchas áreas quedan inexploradas. Peor aún, hay zonas que quedan vedadas y los investigadores curiosos se arriesgan al ostracismo si se aventuran en ellas (véase Redding 2013 para la discusión de un ejemplo reciente en sociología). 
La homogeneidad política en psicología social puede restringir la gama de temas o programas de investigación posibles. Asimismo, nos puede privar de las herramientas y los hallazgos necesarios para abordar importantes problemas sociales. Los dos ejemplos que presentamos a continuación ilustran esta amenaza.

3.2.1. Ejemplo 1: Exactitud de los estereotipos. Desde los años treinta, los psicólogos sociales han venido proclamando la inexactitud de los estereotipos sociales, a pesar de carecer de evidencia respecto de esta inexactitud. La evidencia ha sido considerada innecesaria, ya que los estereotipos han sido calificados como intrínsecamente despreciables y como distorsiones de la realidad (para un revisión, véase Jussim 2012b).

Algunos estereotipos grupales son efectivamente burdos y no verificables. Pero es posible que muchos estén fundados en un empiricismo válido y representen estimaciones subjetivas de las características de una población (por ejemplo, la proporción de estudiantes que deserta de la escuela secundaria es víctima de delitos o respalda políticas a favor de las mujeres en el trabajo; véase Jussim (2012b) y Ryan (2003) para revisiones). En ese contexto, no resulta sorprendente que el estudio empírico riguroso sobre la exactitud de los estereotipos fácticos haya sido iniciado por uno de los pocos investigadores del ámbito de la psicología social que se declara conservador, Clark McCauley (McCauley y Stitt 1978). Desde entonces, docenas de estudios realizados por investigadores independientes han evidenciado que la exactitud de los estereotipos (de todo tipo) constituye uno de los efectos más robustos en toda la psicología social (Jussim 2012b). He aquí un claro ejemplo del valor de la diversidad política: un psicólogo social formuló una pregunta que nadie más pensó o se atrevió a hacer y se topó con resultados que aún incomodan a muchos psicólogos sociales. La determinación de McCauley de someter a una prueba empírica el supuesto de la inexactitud de los estereotipos permitió que se corrigiera uno de los errores más persistentes de la psicología social.

3.2.2. Ejemplo 2: El alcance y la dirección del prejuicio. El prejuicio y la intolerancia han sido considerados por mucho tiempo exclusivos de la derecha política (por ejemplo, Adorno et al. 1950; Duckitt 
2001; Lindner y Nosek 2009). En efecto, desde Allport (1954), los psicólogos sociales han sospechado que existe un tipo de personalidad asociado con el prejuicio generalizado hacia diferentes grupos sociales (Akrami et al. 2011), al que han vinculado con el conservadurismo político (Roets y Van Hiel 2011). No obstante, en años recientes, varios académicos han observado que los grupos habitualmente considerados como blancos de prejuicios en estos programas de investigación son, usualmente, de bajo estatus y muchas veces inclinados a la izquierda (por ejemplo, los afroamericanos y los comunistas; para más ejemplos y argumentos, véase Chambers et al. 2013; Crawford y Pilanski 2014). Utilizando diseños de investigación que incluyen tanto a grupos destinatarios con tendencias de izquierda y de derecha, y valiéndose de muestras nacionalmente representativas y muestras de estudiantes y comunidades, estos investigadores han demostrado que el prejuicio es prevalente tanto en los ambientes de izquierda como de derecha. Los conservadores abrigan prejuicios hacia grupos que de manera sistemática se inclinan hacia posiciones de izquierda (por ejemplo, los afroamericanos). Los liberales, en cambio, abrigan prejuicios contra los grupos que se inclinan de manera constante hacia posiciones de derecha (por ejemplo, los cristianos practicantes; véase Chambers et al. 2013; Crawford y Pilanski 2014; Wetherell et al. 2013).

Resumiendo estos hallazgos recientes, Brandt et al. (2014) propusieron la hipótesis del conflicto ideológico, que sostiene que las personas de todo el espectro político abrigan prejuicios contra quienes profesan credos políticos diferentes. Una vez más, la narrativa compartida de la psicología social parece haber restringido el ámbito de la investigación. Por mucho tiempo, la investigación sobre el prejuicio estuvo limitada a los prejuicios respecto de los objetivos que priman en los intereses liberales. Pero la presencia de un investigador no liberal — John Chambers es libertario- contribuyó a la utilización de diversos objetivos, lo que con el correr del tiempo pudo haber aportado a que el campo desarrollara una visión más matizada de la relación entre política y prejuicios.

\subsubsection{Cómo evitar un énfasis restringido a los temas que pro-} mueven las narrativas liberales. Cuando los investigadores se focalizan principalmente en temas que promueven las narrativas liberales 
o ignoran en forma sistemática las investigaciones inconsistentes con dichas narrativas, se incrementa el riesgo de sesgo político. En vez de asumir que los estereotipos son inexactos sin citar evidencia, cabe preguntarse: “¿Qué tan (in)exactos son los estereotipos? ¿Cuáles son los hallazgos de la investigación empírica?”. En vez de preguntar: “¿Por qué los conservadores tienen tantos prejuicios y son tan políticamente intolerantes?" (Hodson y Busseri 2012; Lindner y Nosek 2009), debiera preguntarse: "¿Qué grupos son objeto de prejuicio e intolerancia en el espectro político y por qué?" (Brandt et al. 2014). No es necesario ser políticamente conservador para formular estas preguntas. De hecho, hasta donde sabemos, por lo menos uno de los autores de la hipótesis del conflicto ideológico (Crawford) se describe como liberal. Por lo tanto, el mero hecho de tener una ideología no conduce necesariamente a investigaciones sesgadas, incluso cuando se abordan temas politizados. No obstante, como lo demostramos más adelante en este artículo, es probable que, al contar con más científicos no liberales, la psicología social podría reducir el tiempo que se toma en corregir errores de larga data en temas politizados.

\subsection{Riesgo 3: Las actitudes negativas hacia los conservadores pueden promover una ciencia social que caracteriza en forma errónea los rasgos y atributos de este grupo}

Un punto de vista que la psicología social-política ha sostenido por mucho tiempo es que la derecha es más dogmática y más intolerante a la ambigüedad que la izquierda, perspectiva que Tetlock (1983) denominó la hipótesis de la rigidez de la derecha. Altemeyer (1996; 1998) argumentó que una de las consecuencias de esta asimetría en la rigidez es que las personas que son de derecha (específicamente aquellas con un alto RWA) deberían ser más propensas a emitir juicios políticos sesgados que las que son de izquierda. Por ejemplo, Altemeyer (1996) halló que los individuos con un alto RWA tenían un sesgo a favor de la oración obligatoria cristiana en escuelas públicas estadounidenses por sobre la oración obligatoria musulmana en escuelas públicas árabes, en tanto que aquellos con un bajo RWA se oponían a la oración obligatoria en las escuelas, independientemente del grupo religioso. Sobre la base de estos y otros resultados, Altemeyer caracterizó a las personas con un alto RWA (que tienden a ser socialmente conservadoras) como hipócri- 
tas y rígidas, y a aquéllas con un bajo RWA (que tienden a ser liberales) como consistentes e imparciales. Otros se han basado en esta evidencia para esgrimir argumentos similares (por ejemplo, Peterson et al. 2002).

¿Pero habían estudiado los científicos sociales un rango suficientemente amplio de situaciones para justificar estas conclusiones generales? La evidencia reciente sugiere que no. El modelo de la premisa ideológicamente objetable (ideologically objectionable premise model, IOPM; Crawford 2012) plantea que las personas de izquierda y de derecha tienen las mismas probabilidades de estar sesgadas frente a un juicio de carácter político. Dicho lo anterior, el sesgo queda en evidencia sólo cuando la premisa de dicho juicio es ideológicamente aceptable. Si es objetable, cualquier preferencia por un grupo sobre otro quedará anulada y los sesgos no se transparentarán. Así, el IOPM permite que se manifiesten los sesgos únicamente entre los liberales, sólo entre los conservadores o entre liberales y conservadores por igual, según el contexto. Por ejemplo, reinterpretando los resultados del estudio sobre la oración obligatoria en las escuelas, Crawford (2012) arguyó que para las personas con un bajo RWA, que valoran la libertad individual y la autonomía, la oración obligatoria en las escuelas es objetable; de esta manera, la propia naturaleza de este juicio u opinión debiese dejar sin efecto los sesgos a favor de un grupo religioso o el otro. Sin embargo, para aquellas personas con un alto RWA, que valoran la conformidad social con los valores morales tradicionales, la oración obligatoria en las escuelas resulta aceptable; la aceptación de esta premisa permite entonces que las personas con un alto RWA expresen un sesgo a favor de la oración cristiana obligatoria en las escuelas frente a la musulmana. Crawford (2012, Estudio 1) reemplazó la oración obligatoria por la oración voluntaria, lo que sería aceptable tanto para las personas con un alto como bajo RWA. En concordancia con el modelo IOPM, las personas con un alto RWA seguían mostrando un sesgo a favor de la oración cristiana versus la musulmana, en tanto que aquellas con un bajo RWA ahora mostraron un sesgo a favor de la oración voluntaria musulmana por sobre la oración cristiana. Por ende, la hipocresía no es necesariamente un fenómeno exclusivo de la derecha.

En otro estudio, Crawford (2012, Estudio 2) argumentó que la izquierda generalmente considera que es aceptable criticar y cuestionar a la autoridad. Por lo tanto, un escenario en el que un subordinado 
critica a una figura de autoridad les permitiría a las personas con un bajo RWA condenar con mayor severidad a un subordinado que critica a un líder ideológicamente similar (por ejemplo, al Presidente Barack Obama) que a uno que critica a un líder ideológicamente diferente (por ejemplo, al Presidente George W. Bush). Sin embargo, criticar a la autoridad es una premisa objetable para aquellas personas con un alto RWA; por lo tanto, deberían condenar con el mismo rigor al subordinado, independientemente de la identidad del líder. En concordancia con el IOPM, las personas con un bajo RWA condenaron con mayor severidad a un general que criticó a Obama que a uno que criticó a Bush, en tanto que las personas con un alto RWA recriminaron por igual al general, independientemente de la identidad del líder. Así, este escenario muestra una inversión de los hallazgos de Altemeyer: los sesgos se evidenciaron entre las personas de izquierda, pero no entre las de derecha. Los resultados obtenidos a partir de siete escenarios respaldan el modelo de la premisa ideológicamente objetable (véase Crawford 2012; Crawford y Xhambazi 2015) e indican que los juicios sesgados de carácter político no se pueden predecir a partir de la orientación ideológica (según lo estipula Altemeyer), sino, más bien, a partir de las cualidades de los escenarios utilizados en la investigación en que se emiten dichos juicios.

Estos ejemplos ilustran las dificultades existentes para establecer una verdad cuando los miembros de un comunidad intelectual políticamente homogénea tienden a percibir al grupo contrario (esto es, a quienes atentan contra la narrativa progresista liberal) en forma negativa. $\mathrm{Si}$ durante el proceso de revisión de pares hubiese más psicólogos sociales que cuestionaran el diseño y la interpretación de los estudios sesgados hacia los valores liberales o si hubiese más investigadores que realizaran sus propias investigaciones con métodos diferentes, los psicólogos sociales podrían tener más confianza en la validez de sus caracterizaciones de los conservadores (y de los liberales).

\subsubsection{Detectar y evitar una caracterización errónea de los rasgos} de los conservadores. Una señal de alerta es la uniformidad de las conclusiones en que se descalifica a los conservadores. Si los resultados empíricos retratan consistentemente a los conservadores en forma negativa y a los liberales en forma positiva, puede ser un indicio de sesgo 
político. Es muy probable que el potencial de sesgo político se reduzca considerablemente cuando los investigadores se esfuercen por explicar las motivaciones, debilidades y fortalezas de los liberales así como las de los conservadores. Varios programas de investigación han arrojado evidencia sobre las fortalezas y debilidades tanto de los liberales como de los conservadores; entre otros, la teoría de los fundamentos morales (por ejemplo, Haidt 2012), el modelo de la premisa ideológicamente objetable (Crawford 2012; Crawford y Xhambazi 2015) y la hipótesis del conflicto ideológico (por ejemplo, Brandt et al. 2014; Crawford et al. 2013; Munro et al. 2010). Esta evidencia invalida la hipótesis de que los conservadores merecen una severa condena científica. Si uno desea focalizarse sólo en los conservadores (o exclusivamente en los liberales), sería teóricamente más productivo comprender sus fortalezas y debilidades; asimismo, se estaría menos sujeto a una acusación de sesgo político.

No es nuestra intención sugerir que los liberales son incapaces de realizar un trabajo equitativo e imparcial al abordar temas delicados. Por ejemplo, varios académicos están elaborando estudios ponderados sobre las reacciones de las personas hacia las figuras de autoridad de izquierda y de derecha (Frimer et al. 2014); el juicio sobre determinadas conductas, o atribución de conducta, formulado en base a valores propios, fenómeno que se da en todo el espectro político (Morgan et al. 2010), y las creencias de las personas sobre el consenso científico en relación a los temas políticos candentes (Kahan et al. 2011), por mencionar sólo unos pocos. No es tampoco nuestra intención impugnar programas de investigación al señalar los problemas específicos que analizamos en los ejemplos anteriores. De hecho, apreciamos la imparcialidad de los planteamientos de algunos de estos autores en otras líneas de investigación (por ejemplo, los estudios sobre la meritocracia y el respaldo a la acción afirmativa de Son Hing et al. 2002). Estas importantes líneas de investigación indican que los procesos de desconfirmación (disconfirmation) en nuestro campo no han perdido toda su vigencia. No obstante, si nos focalizamos en el ámbito en su conjunto y lo visualizamos como un sistema complejo que depende de indagaciones que abordan temáticas amplias y de esfuerzos de desconfirmación institucionalizados, creemos que los parámetros no están correctamente establecidos para alcanzar la verdad en forma óptima. Una mayor diversidad política contribuiría a que el sistema descubriera más verdades. 


\section{POR QUÉ ES PROBABLE QUE LA DIVERSIDAD POLÍTICA CONTRIBUYA A MEJORAR LA PSICOLOGÍA SOCIAL}

La diversidad se puede operacionalizar de muchas formas, entre otras, a través de la diversidad demográfica (por ejemplo, la etnicidad, la raza y el género) y la diversidad de puntos de vista (por ejemplo, la variación en las opiniones intelectuales o la experticia profesional). La investigación en psicología organizacional sugiere que: a) los beneficios de la diversidad de puntos de vista son más consistentes y marcados que los de la diversidad demográfica (Menz 2012; Williams y O'Reilly 1998); y b) los beneficios de la diversidad de puntos de vista son más pronunciados cuando las organizaciones persiguen objetivos abiertos de exploración (por ejemplo, el descubrimiento científico) en oposición a objetivos de explotación (por ejemplo, aplicar rutinas claramente establecidas a problemas bien definidos; Cannella et al. 2008).

La búsqueda de la diversidad demográfica tiene varios beneficios (Crisp y Turner 2011): entre ellos, combatir los efectos de la discriminación, tanto en el pasado como en la actualidad, aumentar la tolerancia $\mathrm{y}$, en los contextos académicos, crear cuerpos docentes demográficamente más atractivos para los estudiantes provenientes de diferentes entornos. Independientemente de cuán socialmente beneficiosos puedan ser dichos efectos, tienen poca relación directa con el proceder o la validez de la ciencia. Por lo tanto, la diversidad de puntos de vista puede resultar más valiosa que la diversidad demográfica si el objetivo principal de la psicología social es generar conclusiones que sean válidas y generalizables. (Por supuesto, la diversidad demográfica puede producir una diversidad de puntos de vista, pero si lo que se persigue es una diversidad de puntos de vista, puede resultar más efectivo buscarla directamente.) Es precisamente la falta de diversidad en materia de puntos de vista políticos lo que hace que la psicología social sea tan vulnerable a los tres riesgos descritos en la sección anterior. Es probable que la diversidad política tenga una serie de efectos positivos, ya que reduce el impacto de dos mecanismos familiares que exploraremos a continuación: el sesgo de confirmación (confirmation bias) y el pensamiento de grupo o consenso mayoritario (groupthink/majority consensus). 


\subsection{El sesgo de confirmación}

Las personas tienden a buscar evidencia que confirme sus propias creencias y a ignorar o minimizar aquella que no sea acorde con dichas creencias. Este sesgo de confirmación (Nickerson 1998) es un fenómeno igualmente prevalente entre la gente común y los científicos (Ioannidis 2012). Es sumamente difícil evitar el sesgo de confirmación en el raciocinio diario; por ejemplo, los cursos para promover la reflexión crítica neutralizan por un tiempo el sesgo de confirmación, pero no lo eliminan del todo (Lilienfeld et al. 2009). Incluso las comunidades de investigación con personas bien intencionadas y de gran inteligencia pueden ser víctimas del sesgo de confirmación, ya que el coeficiente intelectual se correlaciona en forma positiva con el número de argumentos que encuentra una persona para defender sus propios puntos de vista y no con el número de argumentos (mucho más bajo) que encuentran las personas para defender los puntos de vista opuestos (Perkins et al. 1991).

El sesgo de confirmación puede acentuarse todavía más cuando las personas enfrentan temáticas que gatillan emociones morales e inquietudes acerca de la identidad de grupo (Haidt 2001; 2012). Incluso, la polarización grupal suele exacerbar conductas extremas (Lamm y Myers 1978). En efecto, las personas son mucho más diestras para identificar los errores en la evidencia recopilada por terceros que los errores en la propia evidencia, especialmente si esas personas tienen diferentes creencias (por ejemplo, Mercier y Sperber 2011; Sperber et al. 2010). Aunque estos procesos pueden ser fructuosos para comunidades cuyo objetivo es la cohesión social (por ejemplo, movimientos religiosos o activistas), pueden resultar devastadores para las comunidades científicas, ya que conducen a afirmaciones ampliamente aceptadas que, más que reflejar conclusiones científicas, reflejan los puntos ciegos de una comunidad científica (véanse por ejemplo, los tres factores de riesgo que analizamos previamente en este artículo).

El procedimiento de revisión por pares probablemente ofrece mucho menos protección contra el error cuando la comunidad de pares es políticamente homogénea. Idealmente, los revisores debiesen analizar y criticar los métodos de un artículo con el mismo rigor, independientemente de que aprueben o no los hallazgos. No obstante, los sesgos de confirmación pueden llevar a los revisores a esmerarse por encontrar un error en artículos cuyas conclusiones no comparten y a ser más permisivos en 
cuestiones metodológicas cuando están de acuerdo con las conclusiones. Esto es exactamente lo que arrojan los estudios experimentales (Abramowitz et al. 1975; Ceci et al. 1985; ambos descritos más adelante).

De este modo, ciertos supuestos, teorías y hallazgos se pueden transformar en un conocimiento arraigado en un campo disciplinario, no porque sean correctos, sino porque han sido objeto de un menor escrutinio. Cuando la mayoría de las personas de un ámbito específico comparten el mismo sesgo de confirmación, ese campo está más expuesto a llegar a conclusiones injustificadas. La solución más evidente para este problema es que exista un mayor grado de diversidad de opiniones. No se ha encontrado la fórmula para erradicar el sesgo de confirmación en las personas (Lilienfeld et al. 2009), pero podemos diversificar el campo hasta lograr que los sesgos de confirmación individuales comiencen a anularse entre sí.

\subsection{La influencia de la minoría}

La investigación acerca de la influencia de la minoría se ha focalizado en los procesos mediante los cuales la minoría influye sobre el razonamiento de los miembros de la mayoría y, por ende, del grupo (por ejemplo, Crano 2012; Moscovici y Personnaz 1980). Las mayorías influyen en la toma de decisiones mediante la presión a la conformidad, la que genera cohesión y sentido de comunidad, pero que no contribuye a la generación de juicios profundos y de calidad (Crisp y Turner 2011; Moscovici y Personnaz 1980). También existe el riesgo que produzca el tipo de pensamiento grupal que durante largo tiempo ha sido objeto de crítica por parte de los psicólogos sociales (por ejemplo, Fiske et al. 2004; Janis 1972).

En contraste, una minoría discrepante puede minar las normas de cohesión grupal (Crano 2012). Estas normas pueden tornarse disfuncionales para las comunidades científicas, especialmente cuando llevan a sacrificar el escepticismo científico en aras de promover una agenda política (véase Eagly 1995; Jussim 2012a; Redding 2001). Para una comunidad científica, la discordia puede resultar beneficiosa, ya que motiva a los miembros de la mayoría a pensar con mayor profundidad sobre los temas en juego (Crano 2012). En contextos científicos, la lógica o la evidencia de la minoría puede a veces ser tan persuasiva que convence a la mayoría. O bien, si el punto de vista de la mayoría estuvo 
en lo correcto desde el principio, la validez y la credibilidad de dicho punto de vista sale fortalecido al resistir a las tentativas de falsificación por parte de la minoría (Popper 1959; 1968). Los múltiples beneficios de estos procesos se han visto confirmados por las investigaciones sobre la influencia de la minoría, las que señalan que la reflexión más profunda que produce el disenso puede llevar a decisiones grupales de mayor calidad (Crisp y Turner 2011; Moscovici y Personnaz 1980; Nemeth 1995; Nemeth et al. 2001).

Existe evidencia de que los equipos en los que hay diversidad política generan soluciones más creativas que aquellos políticamente homogéneos en relación a problemas del tipo "cómo puede una persona con talento promedio alcanzar la fama" y "cómo conseguir financiamiento para una iglesia parcialmente construida que no puede acceder a un préstamo bancario" (Triandis et al. 1965). Los grupos de a dos personas constituidos por un liberal y un conservador generaron soluciones más creativas a estos problemas que aquéllos en que ambos eran liberales o conservadores. Existe abundante evidencia de que la diversidad de puntos de vista puede - y a menudo lo hace - producir soluciones novedosas para una serie de problemas (Crano 2012; Mannix y Neale 2005). En efecto, algunos cientistas sociales han llegado incluso a presentar los beneficios de la diversidad para la resolución de problemas como una verdad lógico-matemática necesaria y no sólo una verdad empírica contingente (Page 2008, pero véase Tetlock 2007).

En suma, hay motivos para formular la hipótesis de que una mayor diversidad política mejoraría la calidad de la ciencia de la psicología social, generando una mayor divergencia científica, especialmente en relación a temas tan politizados como la desigualdad versus la equidad, las características psicológicas de los liberales y conservadores, y los estereotipos, el prejuicio y la discriminación. Los psicólogos sociales han hecho referencia a estos efectos en muchos contextos. Podrían aprovecharlos para sus propios fines.

\section{5. ¿POR QUÉ HAY TAN POCOS INDIVIDUOS NO LIBERALES EN LA PSICOLOGÍA SOCIAL?}

La pregunta de por qué los conservadores y otros no liberales están subrepresentados en las ciencias sociales es compleja (Klein y Stern 2005) y la evidencia no apunta a una sola respuesta. Para comprender 
por qué los conservadores están tan subrepresentados en la psicología social, consideramos cinco explicaciones que han sido esgrimidas muchas veces para dar cuenta de la falta de diversidad, no sólo en la psicología social, sino también en otros contextos (por ejemplo, la subrepresentación de las mujeres y de las minorías étnicas en el ámbito de la ciencia, la tecnología, la ingeniería y las matemáticas (STEM, por su sigla en inglés); para más detalle, véase Susan Pinker 2008).

\subsection{Diferencias en habilidades}

Gilbert (2011) observó que "una posibilidad bien sopesada es que exista una mayor probabilidad de que los liberales deseen convertirse en profesores. Por ejemplo, puede que los liberales estén más interesados en nuevas ideas, más dispuestos a trabajar por sueldos más bajos o simplemente sean más inteligentes". La evidencia no respalda esta opinión. Antes de ahondar en ella, cabe señalar que una afirmación seria en el sentido de que las diferencias en inteligencia explican la escasez de no liberales tendría sentido sólo si existieran diferencias medibles y consistentes en inteligencia. Para esta afirmación, una diferencia de cinco puntos en puntajes promedios $\mathrm{SAT}^{6}$ no es suficiente. Un hecho notable es que los datos no les otorga una ventaja consistente - ni siquiera modesta - a los liberales. Algunos investigadores han encontrado una leve correlación negativa entre CI y conservadurismo (Heaven et al. 2011; Hodson y Busseri 2012). Sin embargo, otros no han hallado ninguna relación (por ejemplo, entre orientación política y puntajes SAT de matemáticas; Kemmelmeier 2008) o han hallado una relación curvilínea; específicamente, Kemmelmeier (2008) encontró que, a pesar de que, por lo general, el conservadurismo se correlacionaba con puntajes inferiores en las pruebas SAT verbales, el conservadurismo extremo permitía predecir puntajes más altos en las pruebas SAT verbales.

En segundo lugar, la relación observada entre inteligencia y conservadurismo depende en gran medida de cómo se expresa en la práctica el conservadurismo. El conservadurismo social se correlaciona con puntajes inferiores en las pruebas de habilidad cognitiva, pero el conservadurismo económico se correlaciona con puntajes más altos (Iyer et

${ }^{6}$ SAT son las iniciales para Scholastic Assessment Test, prueba estandarizada ampliamente usada para la admisión universitaria en Estados Unidos (N. del E.). 
al. 2012; Kemmelmeier 2008). Del mismo modo, Feldman y Johnston (2014) han detectado en varias muestras representativas a nivel nacional que el conservadurismo social predecía de manera negativa el nivel educativo, mientras que el conservadurismo económico permitía predecir de manera positiva el nivel educativo. En conjunto, estos resultados presumiblemente explican por qué tanto Heaven et al. (2011) como Hodson y Busseri (2012) han encontrado una correlación negativa entre CI y conservadurismo: porque el "conservadurismo" fue traducido en términos operativos como autoritarismo de extrema derecha, que está mucho más relacionado con el conservadurismo social que el económico (Van Hiel et al. 2004). De hecho, Carl (2014) halló que los republicanos tienen una inteligencia verbal media superior (equivalente a hasta 5,48 puntos de CI, si se excluyen las covariables), y este efecto está marcado por el conservadurismo económico (al que, como europeo, denomina liberalismo económico, debido a su defensa del libre mercado). Carl sugiere que los republicanos libertarios compensan con creces la correlación negativa entre conservadurismo social e inteligencia, lo que les brinda una ventaja media total a los republicanos. Más aún, el mayor efecto político del estudio de Kemmelmeier (2008) fue la correlación positiva entre las posturas contrarias a la regulación y los puntajes en las pruebas verbales SAT, donde $\beta=.117, \mathrm{p}<.001$ (a modo de comparación, el coeficiente de regresión para el conservadurismo era $\beta=-.088$, $\mathrm{p}<.01$, y, para ser afroamericano, $\beta=-.169, \mathrm{p}<.001$ ).

En suma, una evidencia sustancial sugiere que los nexos más fiables entre orientación política e inteligencia son las correlaciones positivas tanto del liberalismo social como del conservadurismo económico con la inteligencia verbal, a la vez que no surgen correlaciones consistentes entre las posturas políticas y la inteligencia matemática. Este patrón es incompatible con la hipótesis de que los psicólogos que se consagran a la investigación son, en su inmensa mayoría, liberales de izquierda porque los liberales son más inteligentes que los conservadores.

\subsection{Los efectos de la educación en la ideología política}

Otra explicación respecto de la cantidad desmedida de liberales en el mundo académico es que la educación per se lleva a los estudiantes a volverse más liberales. Por ejemplo, muchos conciben la educación 
como una instancia de "ilustración" y creen que una visión ilustrada se traduce en planteamientos políticos liberales. Existe escasa evidencia de que la educación induzca a los estudiantes a tornarse más liberales. Varios estudios longitudinales, que han seguido durante varios años a miles de estudiantes universitarios, han concluido que la socialización política en la universidad es principalmente producto de la influencia de los pares, no de la educación per se (Astin 1993; Dey 1997). Estos estudios muestran que los estudiantes se vuelven más liberales si están rodeados por pares que son liberales y más conservadores si conviven con pares conservadores. Incluso, el clásico Estudio Bennington (Newcomb 1943) concluyó que era la conformidad con las normas liberales, más que la educación per se, la que llevaba a los estudiantes a volverse más liberales. Por ende, las normas de los grupos de referencia, más que la instrucción educativa per se, inducen a las personas a volverse más liberales en la educación superior.

\subsection{Diferencias en intereses}

Incluso si las diferencias en materia de inteligencia son pequeñas o inexistentes, $¿$ es posible que los liberales encuentren una carrera en psicología social (o la academia, en términos más generales) más atractiva? Sí, por varias razones. Uno de los cinco grandes rasgos de personalidad que se correlacionan más intensamente con el liberalismo político es la apertura a la experiencia $(r=.32$ en el meta análisis de Jost et al. 2003), y las personas que tienen ese rasgo muy marcado tienen más probabilidades de estudiar carreras que les permitirán satisfacer su curiosidad y deseo de aprender, como una carrera en la academia (McCrae 1996). Una carrera académica requiere un doctorado y los liberales ingresan (y se gradúan) en la educación superior más interesados en obtener títulos de doctorado que los conservadores (Woessner y KellyWoessner 2009). Más aún, es probable que las prioridades personales e intelectuales de los liberales los predispongan a una carrera académica. Si se comparan con los conservadores, demuestran menos interés en el éxito financiero y son más proclives a escribir estudios originales y realizar contribuciones teóricas a la ciencia (Woessner y Kelly-Woessner 2009). 
Estas variaciones intrínsecas en intereses pueden verse amplificadas por un efecto de "pájaros de un mismo plumaje". "La similitud produce atracción" es uno de los hallazgos mejor establecidos en la psicología social (Byrne 1969). A medida que un ámbito comienza a inclinarse en un sentido determinado, éste se volverá cada vez más atractivo para personas proclives a esa inclinación. Con el tiempo, es probable que el grupo se caracterice por las personas que lo integran. Es posible que los profesores y los científicos sean percibidos como liberales así como la enfermería es generalmente asociadas con mujeres. Una vez que eso sucede, puede que los conservadores desistan masivamente de unirse a este grupo disímil, basándose en una percepción realista de que "no calzan bien". Gross (2013) se basa en entrevistas y encuestas a académicos de ciencias sociales para afirmar que este tipo de autoselección es la principal razón de que el profesorado se haya vuelto más liberal en las últimas décadas.

La autoselección claramente juega un rol. Pero sería irónico que una comunidad epistémica que hace resonar argumentos empíricos que parecieran exonerarla de actitudes prejuiciosas fuera la misma que rechaza de plano esos argumentos cuando son esgrimidos por otras instituciones para explicar la subrepresentación de las mujeres o de las minorías étnicas (por ejemplo, en las disciplinas STEM u otras profesiones elitistas). Gross (2013) se basa contundentemente en autoinformes de miembros del grupo destinatario sospechoso de conductas prejuiciosas. Pero psicólogos cognitivos y estudiosos del derecho como Greenwald y Krieger (2006) y Kang y Banaji (2006) argumentan que este tipo de evidencia no toma en cuenta los prejuicios inconscientes que, según ellos, son generalizados cuando son rigurosamente evaluados y controlados en entornos de laboratorio. Y sociólogos organizacionales como Reskin (2012) y Bielby (2013) señalan que los obstáculos estructurales para lograr promociones laborales - obstáculos frente a los cuales los empleadores tienden a ser ciegos - pueden también sesgar a los mercados laborales respecto de ciertos grupos específicos. En nuestra opinión, resulta perturbador cuando las exigencias de pruebas que ponen los cientistas sociales y de la conducta para evaluar afirmaciones cambian según quién las emite (Tetlock y Mitchell 2009). La credibilidad de la comunidad científica está en juego. No podemos aspirar a salvaguardar nuestra reputación colectiva si lanzamos acusaciones de prejuicio a 
terceros con argumentos empíricos que desechamos por considerarlos inaplicables a nosotros. Sería una falencia en la prueba de hipótesis de contraste que observadores imparciales considerarían particularmente reprobable.

Dicho esto, las diferencias entre liberales y conservadores en cuanto a rasgos de personalidad y valores, combinados con el efecto de "pájaros de un mismo plumaje", muy probablemente explican parte de la subrepresentación de los conservadores en las ciencias sociales, en general, y en la psicología social, en particular. En teoría, estos efectos podrían explicar todo el desequilibrio, pero no hay un punto de corte claro para los procesos de depuración que Gross (2013) describe. Si éste fuera todo el problema, no debilitaría nuestros argumentos epistémicos acerca de la necesidad de una diversidad política. Ésta última seguiría contribuyendo a mejorar la calidad de la psicología social como ciencia, pero los argumentos morales se verían debilitados. En una sociedad libre, las personas con diferentes preferencias pueden congregarse en diferentes ocupaciones.

¿Y si la autoselección no lo explicara todo? ¿Si el desánimo y la discriminación fueran impuestos a los conservadores por la mayoría liberal? En tal caso, habría razones adicionales para tomar acciones correctivas.

\subsection{Ambiente hostil}

¿Es posible que la autoselección se vea acentuada por una percepción acertada entre los estudiantes conservadores de que no son bienvenidos en la comunidad de los psicólogos sociales? Considérese la narrativa sobre los conservadores que puede armarse a partir de las conclusiones recientes en las investigaciones sobre psicología social: comparados con los liberales, los conservadores son menos inteligentes (Hodson y Busseri 2012) y menos complejos en el plano cognitivo (Jost et al. 2003). Son más rígidos, dogmáticos e inflexibles (Jost et al. 2003). $\mathrm{Su}$ CI inferior explica su racismo y sexismo (Deary et al. 2008) y su defensa de la desigualdad revela por qué son más felices que los liberales (Napier y Jost 2008). Son muy sensibles a las amenazas y a los estímulos negativos (Hibbing et al. 2014; Oxley et al. 2008) y asumen sus posturas políticas en parte para mitigar sus temores y ansiedades (Jost et al. 2003). Estas conclusiones no están confinadas a revistas académicas; 
han sido ampliamente difundidas en la prensa y en libros de lectura masiva sobre las razones que explican por qué los conservadores no creen en la ciencia (por ejemplo, Mooney 2012; Tuschman 2013).

¿Es posible que a medida que los estudiantes conservadores de pregrado se interiorizan con la literatura de investigación en sus clases de psicología social detecten que la disciplina los perciba a ellos y a sus creencias como deficientes? ¿Y qué sucede si asisten a las clases de postgrado y participan en las charlas magistrales, clases y eventos sociales en los cuales casi todo el mundo es liberal? Nosotros mismos muchas veces hemos escuchado burlas y comentarios despectivos de parte de psicólogos sociales sobre los conservadores, no sólo en ambientes informales, sino que también desde el podio, en conferencias y charlas. Los escasos conservadores que se han inscrito en los programas de pregrado también han escuchado estos comentarios y algunos escribieron a Haidt, meses después de su charla de 2011 en la convención de la SPSP, para describir la hostilidad y el ambiente de burla que los obliga a permanecer "en el clóset" respecto de sus creencias políticas o simplemente a abandonar la carrera. Haidt (2011) publicó electrónicamente algunos extractos de estos mensajes ${ }^{7}$ (de manera anónima). El siguiente testimonio, de un ex estudiante de postgrado en un programa selecto de doctorado, es representativo:

No puedo explicarle cuán difícil fue mi paso por la escuela de postgrado por el hecho de no ser un demócrata liberal. A modo de ejemplo, tras la victoria de Bush sobre Kerry, uno de mis profesores me enviaba mensajes por correo electrónico cada vez que aparecía en los periódicos la noticia de otro soldado muerto en Irak; me interpelaba, culpándome públicamente por no haber apoyado a Kerry en las elecciones. Yo era un estudiante de postgrado bastante destacado, pero el entorno ideológico se tornó muy desagradable para mí. En lugar de aspirar a un puesto como docente, como era mi deseo antaño, he optado por abandonar la academia para buscar trabajo en una empresa.

La evidencia respecto de un ambiente hostil no es sólo anecdótica. Inbar y Lammers (2012) les preguntaron a los integrantes de la lista de

${ }^{7}$ Los extractos pueden visualizarse en el blog YourMorals, disponible en: http://www.yourmorals.org/blog/2011/02/discrimination-hurts-real-people/. 
discusión de la SPSP: “¿Consideran que existe un ambiente hostil a sus ideas políticas en su medio?". De 17 conservadores, 14 (82 por ciento) respondieron "sí" (es esto, una respuesta en o sobre el punto medio de la escala, en la cual el punto medio correspondía a "bastante hostil" y el punto superior, a "muy hostil"); la mitad de las respuestas correspondieron a "muy hostil". Este resultado sorprendente sugiere que el ambiente hostil podría afectar negativamente no sólo a los conservadores, sino también a cualquier individuo que no sea liberal o cuyos valores no se alineen con la narrativa progresista de los liberales.

\subsection{Discriminación}

La literatura sobre prejuicios políticos muestra que las personas con posturas partidistas claramente identificadas tienen pocos reparos en expresar su abierta hostilidad hacia el otro bando (por ejemplo, Chambers et al. 2013; Crawford y Pilanski 2014; Haidt 2012). Las personas partidistas piensan que su hostilidad hacia los grupos opositores se justifica por la amenaza que representan para sus valores aquellos individuos que piensan de otra forma (para una reseña, véase Brandt et al. 2014). Es improbable que los psicólogos sociales sean inmunes a esos procesos mentales. En efecto, una amplia evidencia obtenida a partir de diferentes métodos demuestra que los psicólogos sociales efectivamente actúan de manera discriminatoria hacia colegas no liberales en sus investigaciones.

Las investigaciones experimentales han evidenciado sesgos respecto de estudios que contradicen la narrativa progresista de los liberales. Abramowitz et al. (1975) solicitaron a investigadores en psicología que evaluaran la pertinencia de un manuscrito para su publicación. Los métodos y análisis eran idénticos para todos los evaluadores; sin embargo, el resultado era experimentalmente modificado según el caso para sugerir que el grupo de activistas de izquierda de una facultad era mentalmente más sano - o menos- que el grupo de referencia de no activistas. Cuando se señalaba que los activistas de izquierda eran más sanos en términos mentales, los examinadores más liberales le asignaron más méritos al manuscrito para su publicación y consideraron los análisis estadísticos más adecuados que cuando el mismo manuscrito indicaba que los activistas de izquierda eran menos sanos. Los exami- 
nadores menos liberales no demostraron el mismo sesgo (Abramowitz et al. no identificaron ningún examinador conservador).

Ceci et al. (1985) encontraron un patrón similar. Se presentaron propuestas de investigación con hipótesis sobre "discriminación reversa" (es decir, contra personas de raza blanca) o discriminación convencional (contra minorías étnicas) a 150 consejos de evaluación interna. Todos los elementos restantes de las propuestas eran constantes. Las propuestas de "discriminación reversa" fueron aprobadas en menos casos que las de discriminación convencional.

En estos dos estudios de terreno ${ }^{8}$ es muy probable que la discriminación haya sido inconsciente o no intencional. Pero Inbar y Lammers (2012) hallaron que la mayoría de los psicólogos sociales que contestaron la encuesta estaban dispuestos a afirmar de manera explícita que discriminarían a los conservadores. La encuesta planteaba la siguiente pregunta: "Si dos postulantes a un trabajo (con calificaciones similares) estuvieran optando a una vacante en su departamento y usted supiera que uno de ellos es muy conservador, ¿cree que tendería a optar por el más liberal?". De los 237 liberales, sólo 42 (18 por ciento) optó por el punto inferior en la escala, "ningún prejuicio". En otras palabras, el 82 por ciento admitió que sentiría al menos un ligero prejuicio en contra del candidato conservador, y el 43 por ciento se inclinó por el punto

${ }^{8}$ Sólo conocemos un estudio que no logró hallar indicios de discriminación contra los conservadores en el ámbito académico, pero se trata de un trabajo inédito que no incluye departamentos de psicología. Fosse et al. (2011) envió mensajes por correo electrónico a los directores de los estudios de postgrado de las 75 escuelas más prestigiosas de sociología, ciencias políticas, economía, historia y literatura. Los mensajes pretendían ser de potenciales postulantes que señalaban haber trabajado como voluntarios en la campaña de Obama o la de McCain en 2008. Las respuestas no fueron más lentas o frías cuando iban dirigidas a estudiantes que decían haber trabajado para la campaña de McCain. Esto es alentador, pero cabe señalar que los mensajes describían estudiantes que se ajustan al estereotipo general del liberalismo, a saber, personas que quieren especializarse en esa disciplina y valerse de ella para tener un impacto en el mundo y que quieren seguir siendo personas integrales. Sólo una vez que se habían transmitido esas impresiones se revelaba, al final del tercer párrafo, que el estudiante había participado en una campaña presidencial por un par de meses. Más aún, cabe señalar que el director no era una persona anónima, que tenía que responder por sus acciones y que muchas de las respuestas consistían probablemente en textos preparados para lidiar con el gran volumen de solicitudes recibidas por correo electrónico. Pensamos que este estudio incorporó varios elementos de diseño que hicieron menos probable la discriminación. 
medio ("algún prejuicio") o superior. Por el contrario, la mayoría de los moderados (67 por ciento) y de los conservadores (83 por ciento) optaron por el punto inferior en la escala ("ningún prejuicio").

Inbar y Lammers (2012) evaluaron también por otras vías la voluntad explícita de discriminar. Todas arrojaron el mismo resultado: al evaluar una solicitud de beca, 82 por ciento de los liberales admitieron al menos "un ligero sesgo" y 27 por ciento "algo de sesgo" o más. Cuando se trataba de invitar a participar en un simposio, 56 por ciento de los liberales admitieron al menos "un ligero sesgo" y 15 por ciento, "algo de sesgo" o más. La combinación de investigaciones básicas que muestran altos grados de hostilidad hacia personas con ideas políticas contrarias, los estudios de terreno que muestran discriminación contra proyectos de investigación que no simpatizan con las posturas de los liberales y los resultados de las encuestas que indican la voluntad declarada de practicar una discriminación política apuntan a una misma conclusión: la discriminación política es una realidad en el ámbito de la psicología social. Los estudiantes conservadores de postgrado y los profesores ayudantes actúan de manera racional cuando mantienen oculta su identidad política y cuando evitan expresar sus opiniones contrarias, las que podrían ser de enorme beneficio para la disciplina. Es probable que los estudiantes moderados y libertarios estén padeciendo la misma realidad.

\section{RECOMENDACIONES}

En las secciones anteriores de este artículo revisamos evidencia que mostraba que: 1) la psicología social es un campo políticamente homogéneo, con una amplia mayoría de liberales y unos pocos no liberales; 2) esta falta de diversidad puede socavar la validez de la investigación en psicología social de maneras insospechadas, pero muchas veces ocultas; 3) una mayor diversidad política contribuiría a mejorar la calidad de la psicología social como ciencia; y 4) la falta de diversidad tiene sus raíces en una variedad de procesos, dos de los cuales (ambiente hostil y discriminación) son resorte directo de los psicólogos sociales.

Si estas cuatro afirmaciones son correctas, ¿qué puede hacerse para enfrentar las amenazas que plantea la homogeneidad política a una ciencia de calidad? Recomendamos tres tipos de soluciones. Primero, analizamos qué acciones pueden emprender los psicólogos como dis- 
ciplina a través de sus organizaciones y gobernanza. Segundo, analizamos qué pueden realizar los profesores como docentes y como miembros de departamentos académicos. Y tercero, analizamos qué pueden hacer los individuos para reducir el sesgo en su propia investigación y en su evaluación de las investigaciones de terceros. Esta lista es probablemente incompleta e invitamos a otros a brindar nuevas ideas para resolver el problema de la diversidad política en nuestra disciplina.

\subsection{Respuestas organizacionales}

La diversidad es un valor bien establecido en el ámbito académico y que cuenta con un amplio respaldo en la psicología. La American Psychological Association (Asociación Estadounidense de Psicología) ha venido reflexionando sobre formas de promover la diversidad en este ámbito y publicó un importante informe al respecto en 2005. Sus autores se centraron en la diversidad de raza, género, orientación sexual y discapacidad, pero la mayoría de las recomendaciones del informe son válidas para promover también la diversidad política (American Psychological Association 2005). Estas son cinco de las 45 recomendaciones del informe, con ligeras adaptaciones:

1. Formular y adoptar una resolución política contra la discriminación.

2. Implementar un "estudio de clima imperante" respecto de las experiencias, la comodidad/incomodidad de los integrantes y de actitudes/ opiniones/políticas positivas/negativas que los afectan o que afectan a miembros de otras agrupaciones políticas.

3. Ampliar la base de datos del Consejo de Publicaciones y Comunicación (Publication and Communications Board) de investigadores conservadores, moderados y libertarios que tienen conocimientos y experiencia para actuar como revisores ad hoc o participar en consejos editoriales.

4. Realizar un estudio sobre las barreras u obstáculos que enfrentan los estudiantes no liberales en los programas de capacitación, con el propósito de que esos datos sean utilizados posteriormente para establecer sugerencias formales que permitan la capacitación de estudiantes no liberales. 
5. Cada organización debería desarrollar estrategias para promover los programas de capacitación en investigación y conferencias de investigación, a fin de atraer, retener y graduar estudiantes de doctorado y jóvenes profesionales conservadores y no liberales. Éstas pueden incluir premios por disertaciones, financiamiento de viajes para presentaciones y participación en conferencias, y otras formas de apoyo financiero orientadas a estudiantes de postgrado.

Presentamos estos cinco pasos como ejemplos de iniciativas que nuestras organizaciones profesionales ya han realizado para promover la diversidad demográfica. Tal vez más que cualquier otro ámbito científico, los psicólogos entienden los beneficios de la diversidad y cómo lograrla, y podrían fácilmente aplicar estos principios para ampliar la diversidad política.

\subsection{Respuestas docentes}

Los profesores universitarios pueden tomar varias iniciativas para alentar a los estudiantes no liberales a incorporarse a la carrera o para "salir del clóset"9 si ya están cursando sus estudios. Entre otras, señalamos:

1. Generar conciencia. Los docentes pueden afirmar públicamente que la homogeneidad política es problemática en el ámbito académico y declarar de manera abierta su deseo de que esto cambie. Pueden hablar sobre el tema, especialmente en los cursos de postgrado, en las reuniones de profesores que traten sobre contrataciones y promociones, en simposios, coloquios y conferencias, y de manera informal con los colegas.

2. Promover la retroalimentación con no liberales. A pesar de que los estudiantes conservadores se sienten tan a gusto con sus carreras

${ }^{9}$ Asumimos que muchos de los conservadores en el ámbito académico procuran mantener en reserva su identidad política por dos motivos: 1) sólo tres personas de aproximadamente mil levantaron la mano públicamente para declarar que eran conservadores cuando Haidt lo solicitó durante su charla realizada en el marco de la reunión de 2011 de la SPSP. Sin embargo, si la cifra de 6 por ciento obtenida por Inbar y Lammers (2012) es correcta y si la audiencia era representativa de la profesión, deberían haber habido aproximadamente 60 conservadores entre el público; 2) la mayoría de los conservadores que escribieron a Haidt después de su charla de 2011 le declararon explícitamente que mantienen secreta su identidad política. 
universitarias como los estudiantes liberales (lo que indica que no hay una diferencia general en actitud respecto de la educación), se muestran considerablemente menos satisfechos que estos últimos con sus cursos de humanidades y ciencias sociales, es decir, aquellos en los que existe una abrumadora mayoría política de izquierda susceptible de manifestar sus ideas (Woessner y Kelly-Woessner 2009).

Los profesores pueden establecer claramente que están tratando de mejorar las cosas y que están abiertos a recibir mensajes por correo electrónico o visitas a su oficina —o incluso a ser interpelados en clase- de estudiantes conservadores o no liberales. Podrían prologar esa invitación con una discusión sobre los peligros del pensamiento grupal y los beneficios de la diversidad de puntos de vista para la creatividad y la reflexión fecunda.

3. Difundir mensajes alusivos a la diversidad. Los profesores pueden pedirles a sus departamentos que modifiquen el lenguaje de sus sitios web para incorporar la diversidad política a los otros tipos de diversidad, y que en todos sus mensajes inviten a los integrantes de grupos subrepresentados a postular. Si resultara difícil que los programas incorporen ese tipo de mensaje, los profesores pueden hacerlo en sus páginas web personales. Reconocemos que puede sonar irónico promover iniciativas que apunten a una mayor diversidad dirigidas a los no liberales, ya que los liberales históricamente siempre han sido los paladines de la diversidad. Sin embargo, nuestras recomendaciones no están lógicamente constreñidas por una doctrina conservadora y creemos que incorporar más conservadores, libertarios y personas con perspectivas menos categóricas —o sin ningún tipo de afiliación política- puede robustecer nuestra ciencia.

\subsection{Cambios en las prácticas de investigación}

Son muchos los pasos que pueden seguir los investigadores, editores de revistas académicas y reseñadores para reducir los riesgos que supone la homogeneidad política. Es sumamente difícil detectar un sesgo en uno mismo (Pronin et al. 2002), pero si los investigadores logran mejorar su capacidad de pesquisar sesgos entre pares, mejorará la calidad de la investigación. Más aún, una consecuencia potencial de estos cambios en nuestras prácticas científicas podría ser un mayor atractivo en esta disciplina para personas no liberales. 
1. Cuidado con los dobles estándares. Como ya lo hemos demostrado, los hallazgos de investigación que no coinciden con los valores liberales corren el riesgo de ser juzgados con mayor dureza; asimismo, los hallazgos de investigación que respaldan los valores liberales corren el riesgo de ser aceptados sin suficiente revisión crítica. Por ello, cada vez que los investigadores revisan un manuscrito o una propuesta de beca que cubre tópicos con alto contenido ideológico, debieran realizar un ejercicio mental consistente en preguntarse a sí mismos y a los propios colegas cómo reaccionarían frente a investigadores que utilizaran los mismos estándares de evidencia para defender conclusiones ideológicamente contrarias (Tetlock 1994).

2. Apoyar las colaboraciones adversarias. Al promover la colaboración entre personas que manejan diferentes supuestos, podemos orientarnos hacia una ciencia más completa del comportamiento humano (Diaconis 1991). La colaboración entre personas con opiniones encontradas no siempre es fácil (Mellers et al. 2001), y cuando están en juego importantes factores legales o políticos, el asunto se vuelve aún más complejo (véanse las respuestas a Tetlock y Mitchell 2009). Sin embargo, el grupo de trabajo de la SPSP (Funder et al. 2014) recomendó la confrontación de ideas dentro de un equipo en aquellos casos en los que los investigadores no fueran capaces de reproducir los hallazgos de otro equipo. Creemos que ese tipo de colaboración también sería útil para resolver diferencias políticas (naturalmente, dicha forma de trabajar presupone que los psicólogos sociales puedan hallar pares que no sean liberales con los cuales colaborar). Una ciencia ideológicamente equilibrada que recurriera a colaboraciones con personas de otro perfil ideológico para resolver disputas empíricas se asemejaría mucho al modelo ideal de comunidad epistémica de Robert Merton ([1942] 1973) que se autocorrige, una comunidad organizada en torno a las normas de CUDOS. CUDOS es un acrónimo (en inglés) para Comunismo (los datos son propiedad pública), Universalismo (se aplican los mismos estándares de evidencia y de prueba a las afirmaciones, sin importar quién las realiza), Desinterés (vigilancia contra tentaciones ideológicas y comerciales tendientes a falsear la verdad) y Escepticismo Organizado (creación de sistemas de rendición de cuentas para asegurar una aplicación imparcial de las normas). 
3. Practicar las virtudes de CUDOS promueve una cultura cientifica robusta. Las recomendaciones del grupo de trabajo de la SPSP sobre prácticas relativas a las publicaciones y la investigación (Funder et al. 2014) hacen hincapié en la necesidad de contribuir a una cultura científica que ponga el acento en desarrollar una ciencia de calidad. A pesar de que el informe aborda principalmente el tema de las estadísticas y los métodos, hemos demostrado que la validez también requiere prácticas conceptuales y de revisión que sean de calidad. Es también preciso establecer normas que indiquen cómo proceder cuando nuestras afirmaciones científicas demuestran ser erróneas. Los profesores deben reconocer cuando una afirmación es errónea y corregirla para reflejar los nuevos hallazgos de manera más fidedigna (un ejemplo bastante único es Klein (2011)). El Dr. Bruce Alberts, ex presidente de la Academia Nacional de las Ciencias, estableció esto como una prioridad al insistir que los científicos "deben desarrollar un sistema de valores en el cual simplemente dejar atrás nuestros errores sin reconocerlos públicamente sea considerado algo que daña, en lugar de proteger, una reputación científica" (Alberts 2013).

\section{CONCLUSIÓN}

En una época la psicología estuvo dominada por los conductistas, que compartían una cantidad limitada de supuestos sobre lo que constituía la psicología. También controlaban prácticamente todos los hilos de la promoción profesional y la comunicación científica y crearon un ambiente hostil hacia los psicólogos con una orientación más cognitiva. El poderío de los conductistas antes de la revolución cognitiva fue descrito por George Miller: "El poder, los honores, la autoridad, los libros de textos, el dinero, todo en la psicología era propiedad de la escuela conductista... Quienes queríamos ser psicólogos científicos no teníamos cómo oponernos a ellos. Simplemente no hubiéramos conseguido un empleo" (citado en Baars 1986, 203). Sin embargo, esos enfoques disímiles y esas voces disidentes, muchas veces desechadas, denigradas, ignoradas y relegadas a un segundo plano en su momento, fueron cruciales para el progreso de la psicología. Puede que hoy esté sucediendo lo mismo con los enfoques conservadores y no liberales. 
Otros han hecho sonar antes esta alarma (por ejemplo, MacCoun 1998; Redding 2001; Tetlock 1994). Hemos hecho un aporte a esta literatura de tres maneras: 1) Nos hemos basado en un conjunto más amplio de estudios para demostrar que la subrepresentación de los no liberales es creciente (véase el gráfico 1);2) hemos identificado riesgos específicos en el proceso de investigación y mecanismos psicológicos concretos mediante los cuales la diversidad política puede contribuir a mejorar la ciencia de la psicología social (por ejemplo, a través de la influencia de las minorías y ayudando a los investigadores a superar el sesgo de confirmación); y 3) nos hemos basado en un cúmulo de datos nuevos (por ejemplo, Gross 2013; Inbar y Lammers 2012) para brindar un análisis más exhaustivo de las variadas causas que explican la subrepresentación de los no liberales en la psicología social.

No se han producido cambios en respuesta a las alarmas anteriores, pero pensamos que esta vez puede ser diferente. Los psicólogos están abocados a debates profundos y productivos sobre la forma de enfrentar las diversas amenazas a la integridad de sus investigaciones y de su proceso de publicación. Ésta puede ser una oportunidad única para que la disciplina enfrente con rigor los peligros que entraña la homogeneidad política. Pensamos que la necesidad de adoptar medidas es clara y hemos ofrecido sugerencias específicas sobre diferentes formas en que la psicología social puede incrementar su diversidad política y minimizar los efectos del sesgo político sobre su actividad científica.

La necesidad de actuar se hace aún más patente si consideramos cómo se financian nuestras investigaciones. Como el ámbito académico se ha vuelto cada vez más liberal, los no liberales se han vuelto crecientemente desconfiados. Gauchat (2012) halló que los estadounidenses liberales y conservadores confiaban en términos bastante similares en la ciencia desde la década de los setenta hasta comienzos de los noventa. Pero desde mediados de los noventa la confianza de los conservadores se ha desplomado, mientras que la de los liberales ha aumentado. Al revisar las "guerras de la ciencia" de las décadas recientes, Moreno $(2011,18)$ concluye que "el problema para los cristianos evangélicos no es la desconfianza en la ciencia, sino la desconfianza en los científicos". Si la academia se ha vuelto más liberal a la vez que la sociedad estadounidense se ha vuelto más polarizada (Abramowitz 2010), ¿cabe 
sorprenderse que algunos políticos republicanos conservadores aboguen por un recorte al financiamiento de algunas ciencias sociales? Esto ya le ha sucedido a las ciencias políticas: la reciente enmienda Coburn puso severas limitaciones para el acceso a fondos públicos a los cientistas sociales (American Psychological Association 2013). Quisiéramos evitar que la psicología social, o la psicología a secas, sea la próxima víctima. Y el peligro es real: en marzo de 2014, el subcomité para la investigación científica, espacial y tecnológica del Congreso de los Estados Unidos presentó un proyecto de ley (HR 4186), en el que se proponía un recorte de 150 millones de dólares (una reducción del 42 por ciento) en el financiamiento de la National Science Foundation (Fundación Nacional de las Ciencias), apuntando específicamente a las ciencias sociales y del comportamiento. La respuesta de la SPSP fue inmediata, con un llamado a sus miembros para que contactaran a sus representantes en el Congreso y los urgieran a oponerse a esa resolución. Estas iniciativas de los legisladores debieran llevarnos a reflexionar y considerar si acaso esta legislación no es fruto de la percepción de un desequilibrio ideológico en las ciencias sociales.

Nos hemos centrado en la psicología social (y de la personalidad), pero los problemas que describimos ocurren en otras áreas de la psicología (Redding 2001), así como en otras ciencias sociales (Gross 2013; Redding 2013). Afortunadamente, la psicología está especialmente preparada para enfrentar este desafío. Los cinco valores centrales de la APA incluyen "la búsqueda permanente de la excelencia; el conocimiento y su aplicación basados en métodos propios de la ciencia; un servicio impecable a sus miembros y a la sociedad; la justicia social, la diversidad y la inclusión; y la acción ética en todo lo que realizamos" (American Psychological Association 2009). Si la discriminación contra los no liberales existe incluso en un grado medio del descrito en la sección 4 de este artículo y si esa discriminación daña la calidad de algunas investigaciones psicológicas, entonces se están pasando por alto los cinco valores fundamentales. ¿Tolerarán y defenderán los psicólogos el statu quo o la psicología emprenderá los cambios que se requieren para encarnar sus valores y mejorar la calidad de su ciencia? La psicología puede y debe liderar esa senda. 
José L. Duarte, Jarret T. Crawford, Charlotta Stern, Jonathan Haidt, Lee Jussim \& Philip E. Tetlock, "Political Diversity Will Improve Social Psychological Science", Behavioral and Brain Sciences 38 (2015).

\title{
UNA CARACTERIZACIÓN ERRÓNEA DE LA PSICOLOGÍA SOCIAL PARA CONSOLIDAR EL LOABLE OBJETIVO DE AMPLIAR SU DIVERSIDAD POLÍTICA
}

\author{
Alice H. Eagly \\ Departamento de Psicología, Northwestern University \\ eagly@northwestern.edu.
}

\begin{abstract}
Resumen: Los argumentos de Duarte et al. para promover una mayor diversidad política en la psicología social se sustentan en una caracterización errónea de la psicología social, describiéndola como una disciplina incapaz de comprender la veracidad de los estereotipos y los efectos de las actitudes en el procesamiento de información. Corrijo estos malentendidos y me sumo a su idea de que la diversidad política, junto con otras formas de diversidad, pueden beneficiar a la psicología social.
\end{abstract}

Estoy de acuerdo en que una mayor diversidad política en psicología social, al igual que muchas otras formas de diversidad, sería valiosa pues fomentaría la pluralidad de pensamiento en temas sociales. Sin embargo, Duarte et al. plantean esta valiosa idea en una forma acusatoria que no se condice con la investigación y la teoría en este ámbito.

Para dar cuenta del enfoque sesgado del artículo, me baso en el análisis de los autores sobre el supuesto menoscabo de la psicología social, producto de su liberalismo político. El primer ejemplo es su afirmación de que los psicólogos sociales niegan la veracidad de los estereotipos. Esto es falso. Gordon Allport, pionero en la investigación sobre los estereotipos, se refería al "núcleo de verdad" de los estereotipos 
(Allport [1954] 1959, 190), y su matizada teorización llevó a descartar la noción de que los estereotipos son meras ficciones. Consistente con Allport, para comprender la veracidad es necesario diferenciar entre veracidad a nivel grupal e individual (por ejemplo, Ryan 2003). La lógica pura establece que los estereotipos grupales, como promedios mentales de los integrantes del grupo, describen de manera errónea a los individuos atípicos, a pesar de que transmiten una considerable veracidad a nivel grupal. Por ejemplo, al afirmar que los estereotipos de género son "representaciones basadas en datos de la realidad social", Wood y Eagly $(2012,91)$ revisaron varios estudios que muestran que las creencias sobre diferencias y similitudes entre sexos tienen una correlación moderada a alta con los datos empíricos relacionados con los rasgos de personalidad, las habilidades, los comportamientos sociales y las distribuciones ocupacionales de hombres y mujeres (por ejemplo, Hall y Carter 1999). Estos mismos autores también revisaron investigaciones que apuntaban al considerable potencial de los estereotipos grupales para caracterizar erróneamente a los individuos que conforman el grupo.

En lo relativo a una amplia gama de otros estereotipos, Koenig y Eagly (2014) brindaron una robusta evidencia respecto a su fundamento mediante observaciones sobre los comportamientos de los miembros de un grupo. En sus estudios analizaron la hipótesis de que los estereotipos de los miembros de un grupo derivan de las observaciones de las personas respecto de sus comportamientos en los roles sociales en los cuales los integrantes del grupo están sobrerrepresentados en relación a su porcentaje en la población. Sin embargo, ni Koenig y Eagly ni los defensores de la veracidad del estereotipo de género parecen haber despertado la ira de sus colegas de la psicología social.

Pese a la considerable apertura de varios psicólogos sociales en lo relativo a la veracidad de los estereotipos a nivel grupal, la mayoría de las investigaciones sobre los estereotipos están abocadas, no a la veracidad, sino a los efectos negativos de los estereotipos sobre los individuos. Un tema es que los estereotipos perjudican a los personas de grupos de menor estatus que intentan asumir nuevos roles. Es la veracidad descriptiva de los estereotipos la que les confiere el poder de suprimir las aspiraciones de aquellos individuos que se empeñan en romper la rigidez de los estereotipos. Esto puede repercutir negativamente en di- 
chos individuos y generar un mal desempeño en tareas relacionadas con el estereotipo (Steele y Aronson 1995). Otras investigaciones ponen el acento en las diferentes formas en que los estereotipos legitiman el statu quo societal (por ejemplo, Cuddy et al. 2008). Sin embargo, la veracidad a nivel grupal de los estereotipos y su apoyo al statu quo societal son dos caras de la misma moneda.

Otro ejemplo que brindan Duarte et al. acerca del supuesto menoscabo de la psicología social es su afirmación de que dicho campo académico está dominado por una visión que afirma que el prejuicio y la intolerancia son características exclusivas de la derecha política. Para fundamentar este argumento, se basan en unos pocos estudios que arrojan caracterizaciones parciales o unilaterales de los conservadores, pero que luego han sido refutados por otros estudios. En este punto, Duarte y sus colegas parecen no estar familiarizados con el enorme volumen de investigaciones en psicología social sobre los efectos de las actitudes y la ideología en el procesamiento de información (véase Eagly y Chaiken 1998). Uno de los postulados fundamentales de la teoría de las actitudes es que éstas ejercen efectos selectivos en todos los estadios del procesamiento de información. Cientos de estudios han analizado la hipótesis de que las actitudes de las personas generan un sesgo en el procesamiento de la información que juega a favor del material congruente con sus actitudes. Estos efectos de simpatía son comunes en investigaciones sobre la exposición y la atención a información relevante en términos de actitud, y la percepción, el juicio y la evaluación de dicha información. Pese a las complejidades que surgen del duelo entre las presiones hacia la simpatía y las presiones hacia la veracidad (por ejemplo, Hart et al. 2009), ni la teoría de la actitud ni sus hallazgos refuerzan la idea de que los sesgos de simpatía sean exclusivos o más predominantes entre personas de derecha.

Duarte et al. describen acertadamente la psicología social como un campo esencialmente poblado por liberales. Esto se explica por la atracción de estos últimos hacia un ámbito académico que, según ellos, produce conocimiento que puede provocar un cambio social. Como consecuencia de los movimientos sociales de los últimos 50 años, los partidarios de una mayor igualdad en materia de género, raza y etnicidad y orientación sexual se han acercado a la psicología social. Sin 
embargo, su inclinación hacia un cambio social progresivo no se traduce de manera inevitable en un sesgo científico, ya que los científicos en el ámbito de la psicología, sean estos liberales o conservadores, están sujetos a las leyes de la ciencia pospositivista. Cuando un sesgo se hace manifiesto, tiende a corregirse con el tiempo, como lo demuestran los efectos del artículo de Jost et al. (2003).

Duarte et al. estigmatizan el ámbito global de la psicología social debido, en gran parte, a su exageración respecto de la hostilidad de los psicólogos sociales hacia la veracidad de los estereotipos a nivel grupal y su excesivo énfasis en un par de estudios que caracterizan de manera negativa a los conservadores. En suma, su artículo evidencia su falta de conocimiento general de la teoría y la investigación en esta disciplina. Asimismo, ilustran de manera inconsciente uno de los más antiguos principios de la psicología social, a saber, que las actitudes sesgan el procesamiento de información, en este caso potenciando su caracterización altamente selectiva y unilateral de la psicología social. Afortunadamente, han publicado en una revista académica que les permite a terceros enmendar sus errores de juicio.

\title{
“ESPERA ... ¿ERES CONSERVADOR?” LA DIVERSIDAD POLÍTICA Y EL DILEMA DE LA DIVULGACIÓN
}

\author{
$\operatorname{Jim}$ A. C. Everett \\ Departamento de Psicología Experimental, University of Oxford \\ jim.everett@psy.ox.ac.uk.
}

\begin{abstract}
RESUMEN: Muchas de las recomendaciones propuestas para remediar los efectos perversos de la homogeneidad política en la psicología implican que los conservadores revelen su identidad política. Se plantea la interrogante de cuán factible es esto, considerando lo dañino que puede resultar para una persona. Si se considera el problema como un dilema social se aclara su carácter pernicioso y aparecen formas posibles de resolver este dilema.
\end{abstract}

Como lo señalan Duarte y sus colegas en su polémico y esclarecedor artículo, existe una falta impactante de diversidad política en la 
psicología social. Aunque resulte irónico en un campo en el cual uno de los tópicos mayores de estudio es el prejuicio, la academia es manifiesta y sutilmente hostil a los conservadores (Inbar y Lammers 2012; Jussim 2012a). El artículo de Duarte et al. me resulta particularmente interesante, en parte porque fui parte del dos por ciento de estudiantes de postgrado que se autoidentificaron como conservadores en la encuesta de Inbar y Lammers. Concuerdo con los autores en la mayoría de los puntos expresados en su artículo, pero también sostengo que olvidan analizar un tema central para contrarrestar la falta de diversidad en este campo: la divulgación efectiva por parte de las personas de su identidad no liberal. Muchas de las recomendaciones propuestas para mejorar la disciplina se basan en que los conservadores revelen su identidad política. ¿Pero cuán probable es que ello suceda?

Cuando comencé mis estudios de postgrado en psicología tuve que enfrentar un serio dilema: ¿debo intentar esconder mis convicciones políticas conservadoras? Más de un profesor en psicología social me había explícitamente recomendado no revelar mi postura de centroderecha si aspiraba a tener una carrera exitosa en psicología social. El punto de vista que defiendo en este escrito es que revelar la propia identidad política en el presente ambiente debe ser considerado como un dilema social. Considerar esta situación como un dilema social — una situación en la cual los intereses colectivos se oponen a los intereses privadospermite aclarar el carácter pernicioso del problema y sugerir formas para solucionarlo.

Los dilemas sociales tienen dos características fundamentales:

1. Cada individuo recibe una mayor recompensa por desviarse de lo que es de interés colectivo (por ejemplo, usar todos los recursos disponibles para su propia ventaja) que por cooperar, al margen de lo que los demás individuos hagan.

2. El conjunto de individuos está en mejor situación si todos cooperan en lugar de que todos se desvíen (Dawes 1980; Hardin 1968).

¿En qué medida el tema de revelar la propia identidad no liberal constituye un dilema social? Dicho en pocas palabras, un investigador no liberal está en mejor situación no revelando su identidad política, pero el colectivo está en mejor situación si se produce esa declaración pública. 
El primer rasgo de un dilema social es que un investigador recibe una mayor gratificación al desviarse de algo que es de interés colectivo. Dada la hostilidad en el campo, los conservadores políticos están en mejor situación al no revelar su identidad política. Un investigador que aspira a obtener becas, publicar ensayos en revistas académicas prestigiosas y obtener un cargo tendrá más éxito si procura "pretender" que es liberal. Empero, ¿deberían los psicólogos conservadores - y en particular los estudiantes de postgrado- simplemente tratar de esconder sus convicciones políticas? Pienso que no.

El segundo rasgo de un dilema social es que la colectividad está en mejor situación cuando todo el mundo coopera. Si las personas no revelan su identidad política no liberal y los psicólogos sociales conservadores se retiran de ese entorno hostil, el campo disciplinario estará en mucho peores condiciones, lo que afectará a los liberales, conservadores y todas las categorías intermedias. ¿Por qué sucede esto? Como se analiza en el artículo en cuestión, la falta de diversidad es perniciosa para el campo disciplinario por varias razones, entre las cuales cabe destacar las siguientes: los valores y supuestos liberales pueden incrustarse en las teorías y los métodos; es probable que los investigadores se centren en tópicos que validen la narrativa de progreso liberal y eviten aquellos que cuestionen dicha narrativa; las actitudes negativas respecto de los conservadores pueden generar una ciencia que caracterice de manera errónea sus rasgos y atributos.

¿Por qué es necesaria una divulgación para evitar esta tragedia colectiva? En pocas palabras, disponer de psicólogos conservadores públicamente reconocidos como tales es un prerrequisito para algunas de las más importantes soluciones propuestas por Duarte et al. Si no logran ser públicamente psicólogos conservadores, será imposible establecer esquemas de colaboración entre facciones políticas y disponer de un conjunto de psicólogos no liberales que actúen como revisores. En términos más generales, los beneficios de un contacto intergrupal están bien documentados para reducir los prejuicios y promover la cooperación (Allport 1954; Pettigrew y Tropp 2006). Sin embargo, ello está básicamente sujeto a que los miembros de un grupo sean identificados como tales, lo que es imposible si las personas ocultan sus credos políticos. Más aún, es importante que los integrantes de los diferentes grupos se 
destaquen en materia de encuentros intergrupales para que los efectos positivos puedan generalizarse a otros individuos y contextos (Hewstone y Brown 1986). Salvo que los individuos puedan hacer pública su postura antiliberal, perdurará un clima hostil en el que potenciales estudiantes se sienten desalentados por una palpable falta de diversidad. Por ello, es esencial contar con psicólogos abiertamente conservadores para reducir la hostilidad en este campo disciplinario.

En suma, ¿qué debiera hacerse? En su destacado estudio, Messick y Brewer (1983) identifican dos tipos de salidas a los dilemas sociales: soluciones estructurales y motivacionales. Las soluciones estructurales son aquellas que se logran mediante acciones grupales organizadas y que suelen implicar regulación o coerción social para inducir una motivación individual en aras de un interés colectivo. Por el contrario, las soluciones motivacionales individuales se basan en las preferencias de los actores implicados y apuntan a maximizar aquellos factores que llevan a actuar en aras del bien común. Para ayudar a resolver este dilema, se puede recurrir tanto a las soluciones estructurales como a las motivacionales. Ahora bien, resulta excesivo esperar que los conservadores simplemente revelen sus identidades y enfrenten los problemas que se deriven de ello. Por ende, es probable que las soluciones motivacionales orientadas a los conservadores tengan un efecto limitado. Más bien, debe apuntarse a un cambio en las características estructurales de nuestro sistema, para así brindarles el apoyo y los beneficios adicionales a los conservadores y reducir los costos de esta divulgación. Los liberales son los privilegiados en la psicología social y, por ende, son ellos quienes deben asumir el liderazgo para cambiar esta situación.

Tal vez lo más importante que pueden realizar los psicólogos liberales es tomar conciencia de su posición privilegiada en este ámbito académico y cuestionar esta realidad cada vez que sea posible. Son los liberales - no los conservadores - quienes tienen la mayor responsabilidad y el mayor poder para crear un ambiente en el cual se promueva la divulgación de la identidad política y la aceptación de la diversidad. Sólo en esa medida se podrán evitar los efectos desastrosos que la homogeneidad política tendrá en nuestra disciplina. 


\title{
ACTITUDES POLÍTICAS EN ENTORNOS SOCIALES
}

\author{
Andrew Gelman \\ Departamento de Estadística, Columbia University \\ gelman@stat.columbia.edu. \\ Neil Gross \\ Departamento de Sociología, Colby College \\ nlgross@colby.edu.
}

\begin{abstract}
Resumen: Coincidimos con Duarte et al. en que puede resultar valioso estudiar las posturas políticas predominantes en las profesiones. Pero no hemos encontrado evidencia que indique que una mayor diversidad política de la fuerza laboral en las ciencias sociales produzca generalmente mejores investigaciones. También pensamos que, al momento de considerar un equilibrio ideológico, resulta útil ubicar la psicología social en un contexto más amplio de las ideologías de otros grupos de influencia dentro de la sociedad, como la oficialidad militar, los periodistas y los ejecutivos de empresas.
\end{abstract}

A pesar de que valoramos varios aspectos del artículo de Duarte et al, incluida su insistencia en que los cientistas sociales debieran empeñarse en minimizar el impacto en la investigación de sus puntos de vista políticos y su preocupación por las amenazas del mundo político respecto a suprimir el financiamiento a las ciencias, consideramos su argumento central poco convincente. No hemos encontrado evidencia fiable que indique que unas ciencias sociales con profesionales más diversos en lo político tengan estándares más altos de evidencia, sean más capaces de evitar fallas de replicación o, en términos generales, logren producir mejores investigaciones. Como no existen formas estandarizadas de medir estos resultados de forma agregada, y como son escasos los datos fiables sobre las opciones políticas de los investigadores a nivel de las disciplinas y subdisciplinas, nunca han existido - que nosotros sepamos - intentos sistemáticos de examinar la relación entre calidad epistémica y composición política de las comunidades socio-científicas. Por ende, Duarte et al. están abogando por cambios fundamentales en las políticas y las prácticas sobre la base de meras especulaciones. Los autores citan alguna evidencia acerca de los beneficios de una "diversidad de puntos de vista" en la colaboración, pero hay una disparidad de 
escala entre esos estudios (de grupos pequeños) y las generalizaciones a nivel de ámbito académico que realizan los autores. Las investigaciones sobre la historia y sociología de las ciencias sociales sugieren que los movimientos científicos/intelectuales que vinculan los compromisos políticos con los programas de investigación —el tipo de movimiento que, según los autores, ha minado la psicología social y la psicología de la personalidad - han surgido bajo una amplia gama de condiciones políticas, al igual que los movimientos contrarios que abogan por una mayor objetividad. Mientras no dispongamos de mayor información sobre éstas y otras dinámicas relacionadas, sería prematuro abocarse al análisis de las máquinas organizacionales para la producción de conocimiento en las ciencias sociales, sin perjuicio de las preocupaciones que uno pueda sentir, en sintonía con los autores, acerca de ciertas tendencias actuales.

Adicionalmente, creemos que es útil considerar el argumento de Duarte et al. en un contexto más amplio, incorporando otras profesiones que se inclinan de manera marcada a la izquierda o la derecha. La analogía más cercana es tal vez entre profesores universitarios (que son desproporcionadamente demócratas ${ }^{1}$ liberales) y los oficiales del ejército (en su mayoría republicanos conservadores; véase la investigación del cientista social Jason Dempsey (2009)). En ambos casos parece haber un claro vínculo entre entorno e ideología. Las universidades han sido (con notables excepciones) durante mucho tiempo centros de disenso político, así como los militares han sido una institución conservadora (también con algunas excepciones). Y esto es cierto a pesar de que muchos profesores universitarios son bien remunerados y viven cómodamente, y a pesar de que los militares estadounidenses han sido descritos como uno de los últimos bastiones del socialismo en el siglo XXI. Otro ejemplo de profesión pro liberal es el periodismo (con su conocido lema "confortar a los afligidos y afligir a los confortables" y el liberalismo relativo de ese gremio también ha sido confirmado por encuestas a periodistas; por ejemplo, véase Weaver et al. 2003), mientras que los ejecutivos de empresas representan un importante e influyente grupo conservador en la sociedad estadounidense. Ha habido cierto movimiento para contrarrestar el sesgo liberal en el periodismo en los

${ }^{1}$ La expresión se usa para referir a un simpatizante del partido Demócrata de Estados Unidos (N. del E.). 
Estados Unidos, pero no está claro qué podría hacerse para equilibrar la representación política entre los oficiales del ejército y los ejecutivos de las empresas.

En suma, valoramos el trabajo de Duarte et al. en cuanto a analizar las estadísticas e implicancias de las actitudes políticas entre los investigadores sociales. Pero el rubro profesional de los psicólogos, al igual que el de los militares, es una fuerza voluntaria y no nos resulta claro que los supuestos beneficios de corregir el desequilibrio ideológico entre los psicólogos sociales (o entre los oficiales del ejército o los ejecutivos de empresa) compensen los esfuerzos que implicaría llevar a cabo esa tarea. Sea como sea, este tipo de ejercicio probabilístico produce interesantes experimentos reflexivos.

\title{
UN PREDOMINIO DE DEMÓCRATAS AUTODECLARADOS NO CONSTITUYE UNA EVIDENCIA DE UN SESGO IZQUIERDISTA
}

\author{
Benjamin E. Hilbig \\ Laboratorio de Psicología Cognitiva, Universidad de Koblenz-Landau \\ hilbig@uni-landau.de \\ Morten Moshagen \\ Instituto de Psicología, Universidad de Kassel \\ moshagen@uni-kassel.de
}

\begin{abstract}
Resumen: El argumento de Duarte et al. descansa en la premisa básica de que una proporción positiva de demócratas versus republicanos implica un sesgo político. Sin embargo, si lo ponemos en un contexto global e histórico, es evidente que los demócratas estadounidenses representan una posición moderada en el espectro político de izquierda-derecha. Por ende, Duarte et al. no brindan ninguna evidencia de un sesgo izquierdista en la comunidad científica.
\end{abstract}

Es indudable que una marcada asimetría en la distribución de puntos de vista (políticos) relevantes en cualquier comunidad científica puede hacer peligrar la objetividad y el progreso. Duarte et al. sostienen que la mayoría de los psicólogos (en particular, los psicólogos 
sociales y de la personalidad) hoy tienden a autoidentificarse más como demócratas que como republicanos (refiriéndose específicamente a los dos principales partidos políticos existentes en los Estados Unidos) y concluyen que, por ende, la comunidad está sesgada hacia la izquierda. Este razonamiento se basa en el supuesto de que en los Estados Unidos los demócratas se ubican a la izquierda en el espectro político y los republicanos, a la derecha, lo que implica que una posición moderada - y, por tanto, con gran probabilidad, no sesgada — se ubicaría entre las dos, de tal manera que una comunidad sin sesgo ideológico estaría constituida por una proporción aproximadamente equivalente de científicos que se identifiquen como demócratas y republicanos. Sin embargo, como lo demostramos a continuación, este razonamiento es erróneo, pues es producto de una categorización inadecuada del espectro izquierda-derecha, lo que invalida la premisa básica fundamental de Duarte et al.

Para fundar nuestro argumento nos remitimos a una amplia base de datos internacional, longitudinal, de análisis de contenidos de manifiestos de partidos políticos: la base de datos Manifesto, compilada por el proyecto Manifesto Research on Political Representation, que es una de las mayores fuentes de datos en ciencia política comparada (König et al. 2013). En 2003, el proyecto recibió un reconocimiento de la American Political Science Association (APSA) como el mejor conjunto de datos en política comparada. Para mayor información sobre el proyecto, los códigos y otras referencias, se puede visitar el sitio web https://manifestoproject.wzb.eu/. El proyecto se basa en análisis cuantitativos de programas electorales de partidos de más de 50 países, con una cobertura de todas las elecciones libres y democráticas desde 1945. Entrega una estimación de las posiciones de los partidos políticos, en una escala que abarca de la izquierda a la derecha en base a una codificación de cuasi frases correspondientes a diferentes categorías, que dan cuenta de un conjunto predefinido de temas políticos (Budge et al. 2001). Basamos nuestras consideraciones en el logit de la escala izquierda-derecha ("LLR scale"; Lowe et al. 2011) recientemente propuesto.

Duarte et al. caracterizan la década de los ochenta como el punto de inflexión del campo académico hacia una identificación con los demócratas y, por ende, con la izquierda. Sin embargo, las posiciones de los partidos políticos estadounidenses en la escala LLR a lo largo del 
tiempo (véase el gráfico 1) claramente muestran que ambas entidades han virado de manera marcada hacia la derecha del espectro político desde los ochenta. Producto de lo anterior, los demócratas tienen una posición moderada, mientras que los republicanos se posicionan mucho más a la derecha de lo que solían hacerlo. Por consiguiente, el incremento relativo de personas de la comunidad que se autoidentifican como demócratas puede explicarse por el simple hecho de que los científicos tienden a favorecer una posición moderada, equilibrada. Del mismo modo, este incremento de demócratas autoidentificados no puede considerarse como una evidencia de un sesgo pro izquierdista en la comunidad.

Más aún, Duarte et al. conciben la comunidad como si estuviera sólo integrada por científicos estadounidenses (analizando evidencia referida principalmente a estos últimos) y se refieren exclusivamente al espectro político de los Estados Unidos. Sin embargo, según la base de datos de la publicación Web of Knowledge ${ }^{\circledR}$, en el ámbito de la

Gráfico 1. PROMEDIO MÓVIL (3 PERÍODOS) DE LAS POSICIONES DE LOS PARTIDOS POLÍTICOS ESTADOUNIDENSES EN EL LOGIT DE LA ESCALA DE IZQUIERDADERECHA (LLR) A LO LARGO DEL TIEMPO

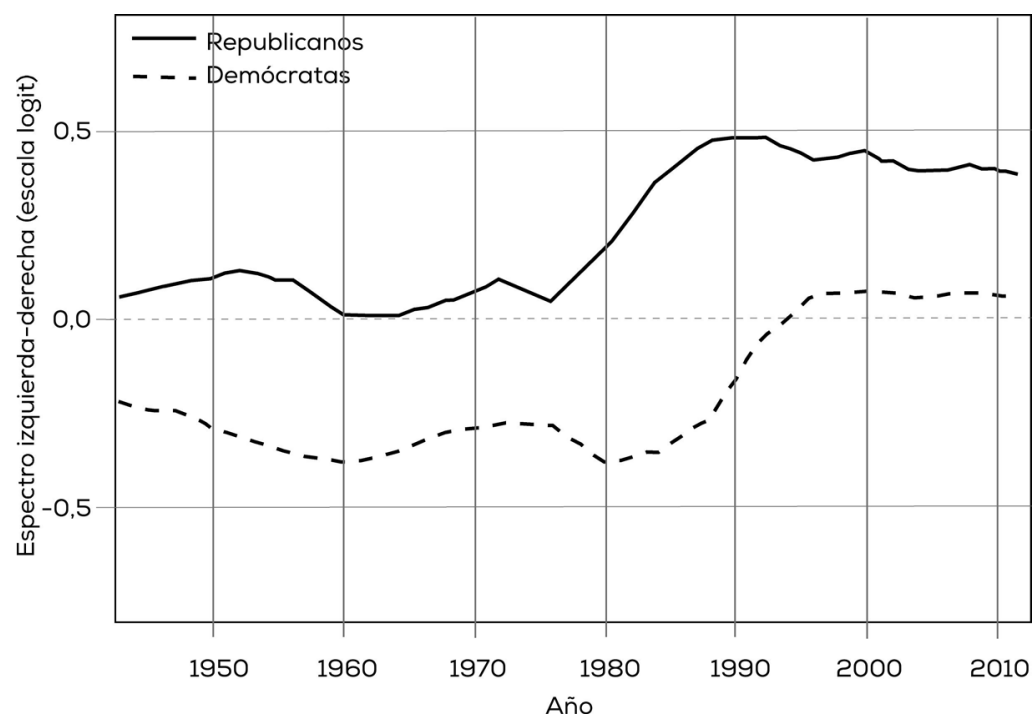

Fuente: Realizado por Hilbig y Moshagen en base a datos de Manifiesto. 
psicología, aproximadamente el 46 por ciento de todos los registros desde 2004 han sido publicados por científicos residentes en los Estados Unidos, mientras que el 46 por ciento restante corresponde a trabajos de científicos del Reino Unido, Alemania, Canadá, Australia, Holanda, España, Italia, Francia, Japón, Suiza, Bélgica y Suecia. (Se obtienen cifras muy similares si se consideran las revistas académicas de mayor impacto en psicología, o las diez revistas de mayor impacto en psicología de la personalidad y social).

Es obvio que los partidos políticos de esos países no calzan con la categorización demócratas versus republicanos de los Estados Unidos. Si se compara la posición de estos dos partidos en la escala LLR con la de los 99 de los doce países mencionados se observa claramente que los demócratas estadounidenses tienen una postura moderada (más que izquierdista) en términos generales (los resultados son prácticamente idénticos si se consideran todos los países incluidos en la base de datos Manifesto). En el gráfico 2 se muestra el porcentaje de votos reales que recibieron los partidos en las elecciones más recientes en función de su posición en la escala LLR. Como puede constatarse, el "punto medio global" (ponderado y no ponderado por los votos reales que recibieron los partidos) es cercano al punto neutro numérico del espectro izquierda-derecha. Esto es esencialmente la posición actual de los demócratas estadounidenses. Por el contrario, los republicanos se ubican aproximadamente en el punto 1 de desviación estándar a la derecha de ese punto medio global. Por ende, si se compara con el espectro político de todos los partidos políticos de los países mencionados (que contribuyen en una misma medida a la ciencia psicológica que los Estados Unidos) resulta claro que el espectro estadounidense (demócratas versus republicanos) sólo puede discriminar dentro de la mitad que se ubica a la derecha en el espectro.

Producto de lo anterior, es probable que las escalas de autoidentificación (en especial aquéllas cuyos extremos están rotulados "liberales" y "conservadores") exhiban el mismo sesgo, ya que estos términos (liberales y conservadores) se interpretan en referencia al espectro político nacional, tal como se expresa en los principales partidos políticos (Benoit y Laver 2006). En términos generales, una proporción positiva de demócratas autoidentificados versus republicanos no puede considerarse como evidencia de un sesgo a la izquierda; por el contrario, una 
Gráfico 2. PORCENTAJE DE VOTOS OBTENIDOS EN LA ELECCIÓN MÁS RECIENTE, CONDICIONADOS POR LAS POSICIONES DE LOS PARTIDOS EN EL LOGIT DE LA ESCALA DE IZQUIERDA-DERECHA (LLR).

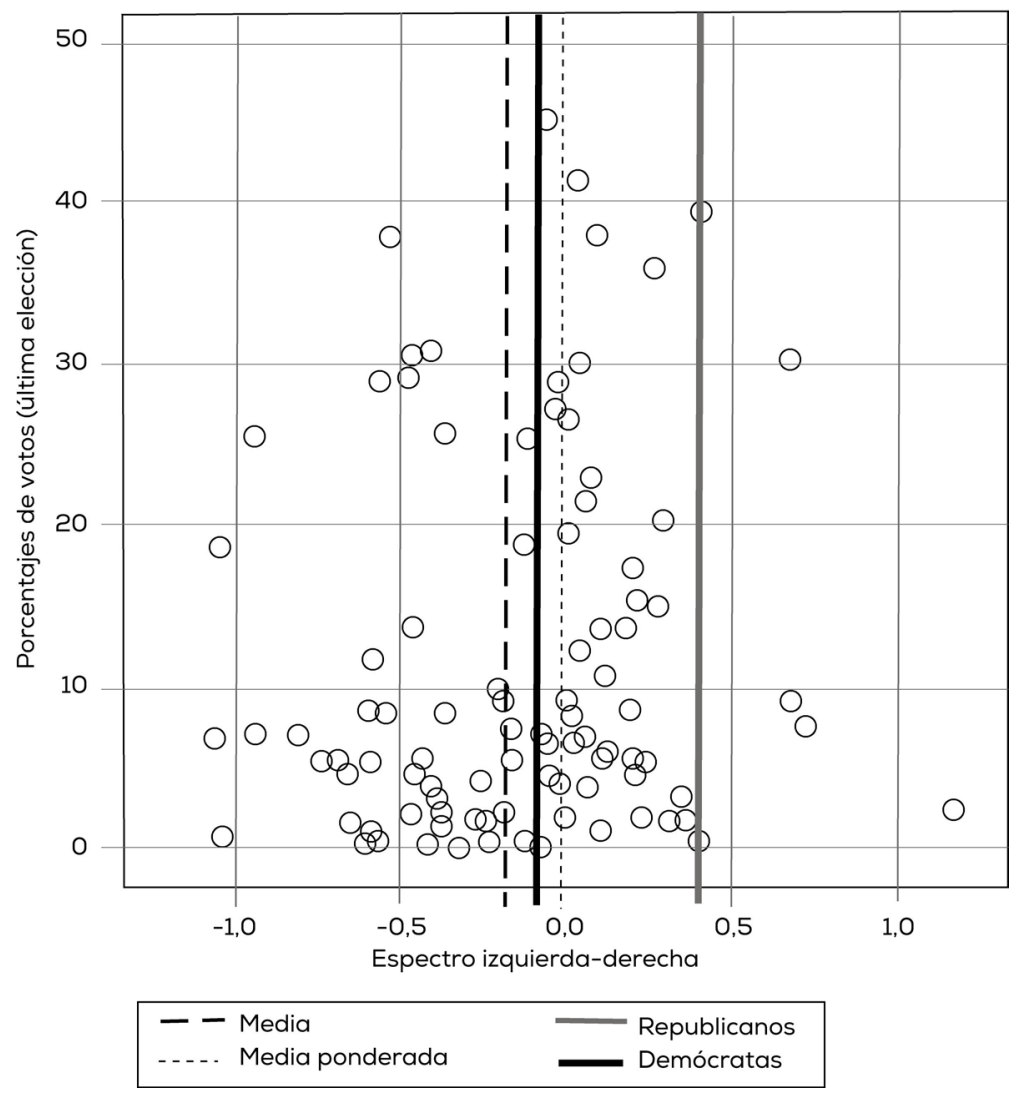

La línea discontinua indica la media no ponderada. La línea de puntos indica la media ponderada. Esta ponderación de las posiciones de los partidos políticos se realiza en función de los votos efectivamente recibidos por los partidos (la media y la mediana difieren en menos de 2 por ciento en la escala). Las líneas llenas indican la posición de los republicanos y demócratas estadounidenses (sólo en la última elección) en la escala LLR.

Fuente: Realizado por Hilbig y Moshagen en base a datos de Manifiesto. 
proporción de ese orden podría equivaler a un sesgo a la derecha. De inferirse algo, podría decirse que la comunidad parece estar alineada con una posición moderada en el espectro izquierda-derecha.

En suma, los datos de Manifesto indican que los demócratas estadounidenses actualmente tienen una posición moderada (más que izquierdista), mientras que los republicanos se sitúan en el ala derecha del espectro político, más de lo que solían y especialmente en términos globales. En consecuencia, referirse exclusivamente a la dicotomía entre demócratas y republicanos constituye una representación muy errónea del espectro político. Así, basados en la evidencia que presentan, Duarte et al. no pueden afirmar que el campo disciplinario muestra un marcado sesgo hacia la izquierda. Esto invalida la premisa básica de su razonamiento.

\title{
ACOGIENDO A LOS CONSERVADORES EN LA DISCIPLINA
}

\author{
Richard Nisbett \\ Departamento de Psicología, University of Michigan, Ann Arbor \\ nisbett@umich.edu
}

\begin{abstract}
RESUMEN: Una mayor presencia de conservadores en la disciplina sería beneficiosa y es probable que los psicólogos sociales no sean tan reacios a incrementar la cantidad de conservadores como opinan Duarte et al. Los problemas de incorporación están principalmente relacionados con la autoselección y los sesgos en la enseñanza de pregrado. Los psicólogos sociales debieran congratularse de contar con conservadores en la disciplina para que sirvan como correa transmisora de nuestras teorías y métodos, dirigida a los intelectuales y diseñadores de políticas conservadores.
\end{abstract}

Concuerdo con Duarte et al. que existe un prejuicio contra los conservadores y que una mayor presencia de conservadores en la disciplina podría representar aportes significativos en lo científico y en lo social.

La analogía con el ingreso de los orientales a la disciplina es clara para mí. Los asiáticos han cambiado profundamente nuestra comprensión sobre la naturaleza del yo y la relación del yo con grupos más 
amplios, como la sociedad. También han influido poderosamente en nuestra reflexión sobre la cognición.

En sus fundamentos, el pensamiento holístico es muy diferente del pensamiento lógico, analítico. Resuelve problemas que el pensamiento analítico es incapaz de solucionar. Los enfoques orientales generan teorías que difícilmente podrían surgir de un pensamiento occidental. Y ambas tradiciones nos brindan un punto de vista estratégico al criticar las prácticas sociales y los hábitos cognitivos del otro. Pienso que algo semejante podría suceder si las ciencias de la conducta incluyeran un mayor número de conservadores. Ello incrementaría el espectro y el carácter de las teorías sociales y de la conducta y brindaría valiosos elementos de crítica.

Como liberal, hay otro motivo por el cual desearía incrementar el número de conservadores en la disciplina. Quisiera que incidamos en el pensamiento social y político de los intelectuales y políticos conservadores. Algunas posiciones conservadoras son simplemente insostenibles a la luz de la teoría consolidada de la psicología social. Basta con mencionar el fundamental error de atribución. También existen oportunidades de incidir en las políticas sociales. Un impulso conservador usual consiste en rechazar cualquier propuesta de intervención so pretexto de que podría haber daños no contemplados futuros o "externalidades negativas". Los psicólogos sociales comprendemos bien estas preocupaciones, pero también disponemos de teorías que pueden ayudar a evitar consecuencias indeseables y disponemos de métodos que pueden evaluar las intervenciones antes de que sean adoptadas a gran escala.

¿Cuán severo es el prejuicio con los conservadores? Como lo reconocen Duarte et al., es difícil saberlo, pues está claro que al menos parte de la razón por la cual hay pocos representantes de ese sector en la disciplina es debido a la autoselección en función de intereses. Pero no cabe duda de que los estudiantes conservadores se pueden sentir desalentados a seguir en parte debido a la actuación de profesores que expresan puntos de vista que en su opinión están respaldados por la teoría y la investigación, pero que en realidad son meros manifiestos de ideología liberal. Y a veces los docentes expresan un abierto rechazo a los puntos de vista conservadores, lo cual, aparte de ser descortés, afecta negativamente nuestra credibilidad frente a personas sensatas de diferentes credos políticos. 
Pero dudo que estemos alejando a muchos potenciales estudiantes de postgrado conservadores. En el futuro inmediato, la autoselección basada en intereses, combinada con un rechazo hacia la ideología liberal de la disciplina serán la principal causa de que sólo una pequeña cantidad de conservadores postulen a la escuela de postgrado. Y un conservador deseoso de ingresar a la escuela de postgrado sabrá que sería imprudente de su parte revelar su posición conservadora en la postulación.

¿Y qué hay de las personas con un doctorado que intentan incorporarse a las facultades de ciencias sociales? ¿Les sería difícil encontrar un trabajo? No me cabe duda de que una posición política conservadora sería una desventaja, pero objeto la evidencia presentada respecto de este punto por Duarte et al. La encuesta de Inbar y Lammers (2012) adolece de fallas. Los investigadores les preguntaron a numerosos psicólogos sociales: "Si dos candidatos a un trabajo (con las mismas calificaciones) postularan a una vacante en su departamento y usted supiera que uno era políticamente bastante conservador, ¿cree que se inclinaría a votar por el más liberal?". El último punto en la escala llevaba como etiqueta "En absoluto". Sólo al marcar ese último punto los encuestados podían demostrar que no tenían prejuicios contra los conservadores. La posibilidad de que un candidato pudiera inclinarse a favor del candidato conservador o tener un sesgo en ese sentido no era tomada en serio o tal vez ni siquiera asumida. Más aún, sabemos que las etiquetas de los puntos en las escalas pueden modificar de manera drástica las respuestas. La escala de Inbar y Lammers podría implicar tácitamente que cualquier cientista social puede, en el mejor de los casos, llegar a ser neutral.

Al menos uno de los autores del artículo aparentemente concuerda con la afirmación de que la neutralidad es a lo más que puede aspirar un psicólogo social. Cuando le señalé que yo sería proclive a votar por el conservador, pareció escéptico. Me sorprendió su reacción. Por todas las razones esbozadas al comienzo de mi comentario, acogería con beneplácito las oportunidades y los desafíos intelectuales que supondría la presencia de un conservador en mi departamento. ( $\mathrm{A}$ pesar de ello, debo admitir que su presencia puede generar algún revuelo en las conversaciones en torno al dispensador de agua!). 
Para determinar si alguien compartía mis preferencias, realicé una pequeña encuesta con 16 prominentes psicólogos sociales. Les pregunté si estarían abiertos a incorporar más conservadores a la disciplina, y si, en igualdad de condiciones académicas, votarían por un candidato conservador o liberal para el trabajo. (Suprimí el adjetivo "bastante" antes de la palabra conservador porque me pareció más razonable comparar a un conservador con un liberal que comparar a un individuo "bastante conservador" con otro meramente liberal.) Hasta donde yo sabía, todos mis encuestados se definían como liberales o moderados. Trece de los 16 afirmaron que incorporarían a conservadores en la disciplina. Sin embargo, hay probablemente un efecto de "no en mi patio trasero" (not in my back yard). Sólo siete afirmaron que votarían por el postulante conservador. Siete indicaron que votarían por el liberal y dos que no tenían ningún favoritismo a priori. Ésta es la prueba de la realidad: hay prominentes psicólogos sociales no conservadores que acogerían conservadores en la disciplina, y algunos de esos psicólogos sociales afirman que no tendrían reparos en contratar a un conservador en su departamento.

En suma, puede que la situación no sea tan negativa como la describen Duarte et al. Su propuesta de volver la disciplina más abierta a los conservadores me parece razonable, posible de llevar a cabo y tal vez más efectiva de lo que ellos asumen. $\mathrm{Al}$ menos, pienso que los psicólogos sociales tomarán en cuenta las admoniciones vertidas en el artículo de Duarte et al. al momento de escribir o dictar una conferencia magistral, y posiblemente incluso cuando elaboren sus propias hipótesis y diseñen pruebas para validarlas. Así lo espero.

\title{
SESGO POLÍTICO, PROFUNDIDAD EXPLICATIVA Y NARRATIVAS DE PROGRESO
}

\author{
Steven Pinker \\ Departamento de Psicología, Harvard University \\ pinker@wjh.harvard.edu
}

RESUMEN: El sesgo político ha sido efectivamente un elemento distorsionador de la psicología, no sólo en determinadas áreas de investigación, sino que también ha contribuido a una aversión a la profundidad explicativa de campos de estudio políticamente cargados, 
como, por ejemplo, la evolución. Agrego dos enmiendas amistosas al artículo revisado: 1) puede que la narrativa moral de izquierda esté más basada en una competencia de suma cero entre grupos identitarios que en un progreso continuo; y 2) el sesgo ideológico debe ser abordado no sólo a través de la diversidad de facciones ideológicas, sino que minimizando la influencia de la ideología.

Puede que este artículo represente uno de los más importantes estudios sobre la práctica de la psicología en la historia reciente de la disciplina. En efecto, el sesgo de izquierda ha sido un elemento sustancial de distorsión en numerosos campos de investigación y teoría. ¡Cómo podría haber sido de otro modo, considerando todo lo que nosotros (especialmente en tanto que psicólogos) sabemos acerca de los efectos intelectualmente corruptores de la ideología, el consenso entre los grupos y la demonización de los disidentes! Duarte et al. documentan y diagnostican brillantemente el problema, a pesar de que su evaluación del daño es sólo parcial. Adicionalmente a los tópicos que mencionan, yo agregaría el estudio sobre las diferencias de sexo, la violencia, los elementos genéticos que contribuyen a la desigualdad económica, los factores culturales que contribuyen a la desigualdad económica y la formación de la personalidad y la inteligencia (véase Pinker 2002; 2011; también Susan Pinker 2008).

El problema se extiende más allá de determinadas áreas de investigación. Sospecho que un sesgo liberal-izquierdista también da cuenta de la ausencia de explicaciones profundas en psicología, como del hecho de que nuestras "teorías" muchas veces consisten en una larga lista de sesgos, falacias, ilusiones, negligencias, cegueras y errores fundamentales, cada uno de los cuales redescubre el hallazgo de que los seres humanos son inaptos en algún ámbito. Para explicar por qué los individuos son inaptos en determinados ámbitos y aptos en otros, la psicología debe invocar principios de disciplinas que son más fundacionales, como la economía, la genética y la biología de la evolución. Pero estas fuentes de profundidad explicativa son muchas veces descartadas por los psicólogos debido a su supuesta carga política (Pinker 2002).

Además de afectar la psicología científica, el sesgo político identificado por Duarte et al. ha corroído la confianza global en la ciencia. Para tomar un ejemplo funesto, los escépticos del cambio climático antropogénico suelen contradecir el consenso científico afirmando que 
el sesgo izquierdista de los investigadores es tan marcado y tan poco reconocido que nada que provenga de la academia puede ser asumido como verdadero. Están ciertamente equivocados acerca de la ciencia climatológica, pero nuestra disciplina ha dado claros ejemplos de que ese sesgo existe. Uno de ellos es el enorme revuelo y la ausencia de debate razonable tras los comentarios de Lawrence Summers del 2005 sobre la interpretación de la evidencia relativa a la discriminación de género en la academia (véase Pinker 2005).

Las ciencias sociales deben volver a una indagación ajena a intereses políticos y el artículo comentado es un llamado oportuno a actuar. Agregaría dos objeciones amistosas.

En primer lugar, no estoy seguro de que la narrativa de progreso liberal de Christian Smith sea un resumen totalmente exacto de la orientación política de los cientistas sociales. Habiendo yo mismo documentado de que existe una gran cantidad de verdad empírica para la narrativa misma - hemos hecho efectivamente, mucho progreso desde la Ilustración (Pinker 2011) - , puedo afirmar que los liberales de izquierda contemporáneos lo niegan abiertamente (a pesar de que sí creen que vale la pena luchar por ese progreso). ¿Abolición de la esclavitud? Muchas veces me entero de que hay muchos más esclavos hoy que en cualquier otra época. ¿Fin de la segregación racial? Las cárceles estadounidenses son el nuevo Jim Crow. ¿Menos racismo? Éste se muestra solapadamente bajo la forma de sesgos implícitos. ¿Los derechos y la salvaguarda de las mujeres? Las barreras se han vuelto más invisibles y las mujeres ahora corren más peligro que nunca, especialmente una de las cada cuatro mujeres que son violadas en los campus universitarios. ¿El fin del barbarismo de los castigos corporales? Vivimos en una sociedad carcelaria semejante al panóptico cuyas sutiles formas de vigilancia y sumisión vuelven superfluas las hogueras para quemar personas.

Hoy son los libertarios, y no los liberales de izquierda, quienes tienden a creer en el progreso (por ejemplo, Ridley 2010). En vez de hablar de progreso liberal, la narrativa de muchos académicos izquierdistas consiste en afirmar que la sociedad es una competencia de suma cero entre clases, géneros y razas, y que una misión a la cual vale la pena consagrar la vida es asegurar que los grupos hoy desaventajados obtengan la parte que les corresponde de poder y recursos. Por estos 
motivos, la reiterada referencia de Duarte et al. a la "narrativa de progreso liberal" parece errar el blanco. Ninguno de los ejemplos de sesgo político que enuncian presupone una convicción de que nuestra sociedad ha progresado.

Una segunda observación: los autores tuvieron una chispa de genialidad retórica al usar el santo y seña (shibboleth) liberal izquierdista de la "diversidad" contra los propios liberales, y plantean la interesante idea de que algún tipo de acción afirmativa para los conservadores y los libertarios podría ayudar a neutralizar el sesgo. Pero la analogía entre raza y género, por un lado, e ideología política, por el otro, es parcial, en el mejor de los casos. A pesar de lo que digan Gilbert y Sullivan, uno no nace liberal o conservador de la misma forma en que nace hombre o mujer, europeo o asiático o africano. Las ideologías políticas no son marcadores arbitrarios; tienen un contenido intelectual que puede ser expuesto, debatido y, cuando corresponde, descartado. Todos los cientistas deberían hacer esto, incluidos los liberales y la gente de izquierda; no debiéramos asumir que los izquierdistas están predeterminados para sesgar su ciencia hacia la izquierda, lo que requeriría una facción de derechistas que los neutralizaran con un sesgo opuesto. Sería una lástima si esa sugerencia táctica de los autores generara un debate erróneo sobre los méritos de las cuotas y la discriminación inversa y opacara la idea central de que el manejo de una ciencia adecuada requiere que hagamos todo lo posible para identificar y minimizar las distorsiones de ideologías parroquiales.

\title{
¿DE QUÉ TIPO DE CONSERVADORES CARECE LA PSICOLOGÍA SOCIAL Y POR QUÉ?
}

\author{
Lee Ross \\ Departamento de Psicologia, Stanford University \\ Iross@stanford.edu
}

Resumen: A pesar de que los argumentos de Duarte et al. acerca de los potenciales beneficios de una mayor diversidad política en el ámbito de la psicología social son válidos, su análisis sobre el declive de dicha diversidad, el rol que juega la autoselección y los ámbitos específicos que citan al analizar el sesgo anticonservador plantean 
interrogantes que ameritan un mayor análisis. También se rebate su afirmación de que las investigaciones y los estudios serios que cuestionan las ortodoxias liberales no tienen cabida en nuestras revistas académicas y en nuestro discurso profesional.

Los individuos de todo el espectro político tienden a ver la evidencia y los argumentos a través del prisma de sus razonamientos y valores, y a presionar en favor de una mayor uniformidad. Por ello, es imposible disentir de la idea de que una mayor diversidad política en nuestro ámbito académico (así como otros tipos de diversidad) nos beneficiaría. Dicho esto, quisiera comentar tres puntos planteados en el artículo revisado que, en mi opinión, ameritan una mayor consideración.

La pérdida de psico-diversidad política. Los términos "liberal" y "conservador" en el actual escenario político estadounidense tienen un sentido diferente del que tenían cuando el campo incluía más conservadores autodeclarados y más republicanos (moderados). Las creencias que caracterizaban a los seguidores de Eisenhower y Nixon - a saber, conservadurismo fiscal y defensa de un cambio social gradual y no radical (para qué decir nada de aceptar una estructura tributaria altamente progresiva) - no describen el tipo de conservadurismo al que aluden Duarte et al. cuando hablan de subrepresentación. Los investigadores sociales que asumen esos puntos de vista tradicionales del Partido Republicano, pero que, sin embargo, creen que el Estado debe jugar un rol activo en atender las demandas sociales y que se sienten conformes con la ampliación de derechos a los homosexuales y la libertad de las mujeres para abortar, no son muy proclives a autodenominarse "conservadores", menos aún si son medidos con la misma vara que aquellos que rechazan estos puntos de vista. Los autores no presentan evidencia, empírica o incluso anecdótica, de hostilidad hacia formas más tradicionales de conservadurismo (como las que suscriben los partidos conservadores en el Reino Unido o Canadá). En breve, aquello que está en gran medida ausente y que es rechazado por la psicología social (y en nuestras universidades de élite) es una forma particular de conservadurismo, muy marcada por la corriente evangélica del cristianismo y/o por el resentimiento y la resistencia a los cambios en la demografía y las costumbres sociales de los Estados Unidos.

Curiosamente, Duarte et al. no parecen prestar atención a la virtual desaparición de nuestras filas de académicos con enfoques más a la 
izquierda que los de los clásicos demócratas liberales estadounidenses, a saber individuos que no aceptan la idea de que una combinación de capitalismo (incluso con mayor regulación) y democracia es la única senda imaginable hacia una sociedad armónica.

La autoselección y la política de la psicología social. Duarte et al. tienen razón cuando señalan que la autoselección es el origen de la sobrerrepresentación liberal. Algunos de los principios centrales de la psicología social son claramente más llamativos para los estudiantes que desean explorar las fuentes de los males sociales y sus remedios potenciales que para los que desean preservar el statu quo. No cabe duda de que los profesores liberales tienden a escoger ejemplos, tanto en su práctica en aula como en su investigación, en los cuales las debilidades de los conservadores, más que las de los liberales, son presentadas como casos dignos de estudio. Pero Duarte et al. citan escasa o ninguna evidencia que indique que los informes de investigación que se centran en la susceptibilidad de los liberales a determinados sesgos, o que documentan una susceptibilidad mutua, están expuestos a menos escrutinio crítico de revisores y editores (en comparación con las personas que responden a encuestas o los participantes en las investigaciones) que aquellos informes sobre susceptibilidad conservadora.

Duarte et al. no mencionan que algunos de los estudios más valorados en nuestro ámbito - especialmente en educación - contienen hallazgos muy consistentes con valores conservadores tradicionales, como la persistencia frente a la adversidad y un sentido de responsabilidad personal y autoeficacia. La mayoría de los estudios aplicados en psicología social son en realidad más reformistas que liberales en espíritu. Las demostraciones de que unas pequeñas intervenciones pueden dar frutos (Walton 2014; Walton y Cohen, 2011) vienen a cuestionar tanto las afirmaciones izquierdistas de que las personas desfavorecidas no pueden mejorar su situación sin cambios estructurales a nivel social, como la noción derechista de que los malos resultados de una persona se deben fundamentalmente a una falta de motivación, habilidades o carácter.

Ejemplos mal escogidos de sesgo liberal. El vínculo entre ideología conservadora, por un lado, y resistencia a la evidencia sobre cambio climático y sus orígenes antropogénicos, y, por ende, el rechazo a los llamados a actuar, por otro, no es en absoluto obvio. (Más aún, ese vínculo 
está en gran medida circunscrito a los Estados Unidos). El cuidado del planeta, la preservación del statu quo biológico y la conservación de los recursos son obligaciones que uno esperaría que los conservadores tomaran más en serio que los liberales. La pregunta de por qué y cómo la negación del cambio climático se ha transformado en un sello distintivo de muchos republicanos conservadores es un desafío interesante y oportuno para los cientistas sociales. (Yo sugeriría "sigan al dinero"). Pero considerando dónde yace el peso de la prueba, una falta de imparcialidad en el tratamiento de los estudios que producen los dos lados de este debate no constituye una evidencia contundente de un sesgo anticonservador. Otros ámbitos (educación, vigilancia policial, economía del bienestar) seguramente brindarían un terreno mas fértil en la búsqueda de evidencia de que los editores de revistas y las agencias que asignan fondos no están dispuestos a respaldar los trabajos que desafian la ortodoxia liberal con datos convincentes.

En lo que respecta a la veracidad del estereotipo, el análisis que brindan Duarte et al. carece de perspectiva histórica. El concepto original de estereotipo era más que el supuesto de alguna relación estadística entre la participación en un grupo y una característica negativa (o positiva). Más bien, se refería a la creencia simplista de que todos o casi todos los miembros de un grupo específico comparten alguna característica, como una cualidad esencial (Lippman 1922). La pregunta de si los tipos de estándar que Duarte et al. citan reciben más o menos pesos que el que ameritan en términos bayesianos - y por quién- es una interrogante empírica que probablemente merece ser investigada (a pesar de que la respuesta muy probablemente depende del grupo y de la característica estipulada). Pero esa pregunta no fue la que motivó a los investigadores en ciencias sociales a abordar el fenómeno del estereotipo. Su preocupación fueron las consecuencias de los estereotipos para quienes los padecen y para aquellos que los sostienen. Las referencias a estereotipos "no veraces" simplifican en extremo el tema, pero también lo hacen las afirmaciones que indican que determinados estereotipos son "veraces", especialmente en ausencia de un debate sobre los factores que producen y sostienen las diferencias relevantes en acciones y resultados.

Conclusiones. Sería beneficioso para la psicología social que conservadores juiciosos (y otros cuestionadores juiciosos de la ortodoxia) 
participaran más en nuestras revistas académicas y que el tipo de "corrección política" que limita la indagación y la discusión en clase fueran menos evidentes. Es muy probable que los estudios y argumentos deficientes que dan confort a las ortodoxias liberales estén menos sometidos al escrutinio crítico que aquellos que respaldan creencias conservadoras. Más preocupante sería hallar evidencia (cosa que no logré en el artículo de Duarte et al.) que indique que estudios sólidos que apoyen creencias conservadoras o que cuestionen las ortodoxias liberales no tuvieran una merecida audiencia o el debido apoyo dentro de nuestra disciplina. En efecto, la seriedad con la que los psicólogos sociales han asumido los temas planteados por los autores del presente artículo y otros estudios que citan muestran que las voces disidentes reciben difusión y generan un encendido debate.

\section{REFERENCIAS CITADAS EN ARTÍCULO PRINCIPAL Y COMENTARIOS CRÍTICOS}

(La letra [a], entre corchetes, señala que se trata de una fuente del artículo principal. Otras iniciales entre corchetes refieren al comentarista que utilizó aquella fuente.)

Abramowitz, A. I. 2010. The disappearing center: Engaged citizens, polarization, and American democracy. Yale University Press. [a]

Abramowitz, S. I., B. Gomes \& C. V. Abramowitz. 1975. "Publish or politic: Referee bias in manuscript review". Journal of Applied Social Psychology 5 (3): 187-200. 10.1111/j.1559-1816.1975.tb00675.x. [a]

Adorno, T., E. Frenkel-Brunswik, D. J. Levinson \& R. N. Sanford. 1950. The authoritarian personality. Harper. [a]

Akrami, N., B. Ekehammar \& R. Bergh. 2011. "Generalized prejudice: Common and specific components". Psychological Science 22 (1): 57-59. [a]

Alberts, B. 2013. "Trouble at the lab", The Economist, 19 de octubre de 2013. http://www.economist.com/news/briefing/21588057-scientists-think-scienceself-correcting-alarming-degree-it-not-trouble. [a]

Allport, G. W. 1954. The nature of prejudice. Addison-Wesley. [a, JACE]

—. (1954) 1979. The nature of prejudice. Perseus Books. [AHE]

Altemeyer, B. 1996. The authoritarian specter. Harvard University Press. [a]

- 1998. "The other authoritarian personality". Advances in Experimental Social Psychology 30: 47-92. [a] 
American Psychological Association. 2005. “APA presidential task force on enhancing diversity". http://www.apa.org/pi/oema/resources/taskforce- report. pdf. [a]

—. 2009. "Strategic plan". http://www. apa.org/about/apa/strategic-plan/. [a] . 2013. "Coburn amendment restricts NSF political science funding". http:// www.apa.org/science/about/psa/2013/04/political-science-funding.aspx. [a]

Astin, A. W. 1993. What matters in college? Four critical years revisited. JosseyBass. [a]

Baars, B. J. 1986. "The cognitive revolution in psychology. Guilford Press. [a]

Barber, M. \& McCarty, N. 2013. "Causes and consequences of polarization”. En Negotiating agreement in politics, editado por J. Mansbridge \& C. J. Martin, 19-53. American Political Science Association. [a]

Benoit, K. \& M. Laver. 2006. Party policy in modern democracies. Routledge. [BEH]

Bielby, W. 2013. "Minority vulnerability in privileged occupations". American Academy of Political and Social Science 639: 12-31. [a]

Brandt, M. J., C. Reyna, J. R. Chambers, J. T. Crawford \& G. Wetherell. 2014. "The ideological-conflict hypothesis: Intolerance among both liberals and conservatives". Current Directions in Psychological Science 23 (1): 27-34. [a]

Budge, I., H.-D. Klingemann, A. Volkens, J. Bara \& T. Eric. 2001. Mapping policy preferences: Estimates for parties, electors, and governments 1945-1998. Oxford University Press. [BEH]

Byrne, D. 1969. "Attitudes and attraction". Advances in Experimental Social Psychology 4: 35-89. [a]

Cannella, A. A., J. H. Park \& H. U. Lee. 2008. “Top management team functional background diversity and firm performance: Examining the roles of team member collocation and environmental uncertainty". Academy of Management Journal 51 (4): 768-84. [a]

Carl, N. 2014. "Verbal intelligence is correlated with socially and economically liberal beliefs". Intelligence 44: 142-8. [a]

Ceci, S. J., D. Peters \& J. Plotkin. 1985. "Human subjects review, personal values, and the regulation of social science research". American Psychologist 40 (9): 994-1002. [a]

Chambers, J. R., B. R. Schlenker \& B. Collisson. 2013. "Ideology and prejudice: The role of value conflicts". Psychological Science 24 (2): 140-49. [a]

Clark, C. F., M. J. Kotchen \& M. R. Moore. 2003. "Internal and external influences on pro-environmental behavior: Participation in a green electricity program". Journal of Environmental Psychology 23: 237-46. [a]

Crano, W. D. 2012. The rules of influence: Winning when you are in the minority. St. Martin's Press. [a]

Crawford, J. T. 2012. "The ideologically objectionable premise model: Predicting biased political judgments on the left and right". Journal of Experimental Social Psychology 48 (1): 138-51. [a] 
Crawford, J. T. \& E. Xhambazi. 2015. "Predicting political biases against the Occupy Wall Street and Tea Party movements". Political Psychology 36 (1): 111-21. doi:10.1111/pops.12054. [a]

Crawford, J. T. \& J. M. Pilanski. 2014. "Political intolerance, right and left". Political Psychology 35 (6): 841-51. doi:10.1111/j.1467-9221.2012.00926.x. [a]

Crawford, J. T., S. A. Modri \& M. Motyl. 2013. "Bleeding-heart liberals and hardhearted conservatives: Subtle political dehumanization through differential attributions of human nature and human uniqueness traits". Journal of Social and Political Psychology 1 (1): 86-104. doi:10.5964/jspp.v1i1.184. [a]

Crisp, R. J. \& R. N. Turner. 2011. "Cognitive adaptation to the experience of social and cultural diversity”. Psychological Bulletin 137 (2): 242-66. [a]

Cuddy, A. J. C., S. T. Fiske \& P. Glick. 2008. "Warmth and competence as universal dimensions of social perception: The stereotype content model and the BIAS map". En Advances in Experimental Social Psychology, volumen 40, editado por M. P. Zanna, 61-149. Elsevier. http://dx.doi.org/10.1016/S0065-2601(07) 00002-0. [AHE]

Dawes, R. M. 1980. "Social dilemmas”. Annual Review of Psychology 31 (1): 16993. [JACE]

Deary, I. J., G. D. Batty \& C. R. Gale. 2008. "Bright children become enlightened adults". Psychological Science 19: 1-6. [a]

Dempsey, J. K. 2009. Our army: Soldiers, politics, and American civil-military relations. Princeton University Press. [AG]

Dey, E. L. 1997. "Undergraduate political attitudes: Peer influence in changing social contexts". Journal of Higher Education 68 (4): 398-413. [a]

Diaconis, P. 1991. Comentario a "Replication and Meta-Analysis in Parapsychology”, de J. Utts. Statistical Science 6 (4): 386. [a]

Duckitt, J. 2001. "A dual-process cognitive-motivational theory of ideology and prejudice". Advances in Experimental Social Psychology 33: 41-113. [a]

Dunlap, R. E., K. D. van Liere, A. G. Mertig \& R. E. Jones. 2000. "Measuring endorsement of the New Ecological Paradigm: A revised NEP scale". Journal of Social Issues 56: 425-42. [a]

Eagly, A. H. \& S. Chaiken. 1998. "Attitude structure and function". En The handbook of social psychology, volumen 1, editado por D. T. Gilbert, S. T. Fiske \& G. Lindzey, 269-322. McGraw-Hill. [AHE]

Eagly, A. H. 1995. "The science and politics of comparing women and men". American Psychologist 50: 145-58. [a]

Feldman, S. \& C. Johnston. 2014. "Understanding the determinants of political ideology: Implications of structural complexity". Political Psychology 35 (3): 337-58. [a]

Feygina, I., J. T. Jost \& R. E. Goldsmith. 2010. "System justification, the denial of global warming, and the possibility of system-sanctioned change". Personality and Social Psychology Bulletin 36 (3): 326-38. [a] 
Fiske, S. T., L. T. Harris \& A. J. C. Cuddy. 2004. "Why ordinary people torture enemy prisoners". Science 306 (5701): 1482-83. [a]

Fosse, E., N. Gross \& J. Ma. 2011. "Political bias in the graduate admissions process: A field experiment". Working paper, Harvard University, marzo 2011. [a]

Frimer, J. A., D. Gaucher \& N. K. Schaefer. 2014. "Political conservatives' affinity for obedience to authority is loyal, not blind". Personality and Social Psychology Bulletin 40 (9): 1205-14. [a]

Funder, D. C., J. M. Levine, D. M. Mackie, C. C. Morf, C. Sansone, S. Vazire \& S.G. West. 2014. "Improving the dependability of research in personality and social psychology: Recommendations for research and educational practice". Personality and Social Psychology Review 18: 2-12. [a]

Gauchat, G. W. 2012. "Politicization of science in the public sphere: A study of public trust in the United States, 1974 to 2010". American Sociological Review 77 (2): 167-87. [a]

Gilbert, D. 2011. Comentario a "The bright future of post-partisan social psychology", charla de J. Haidt. Edge, 11 de febrero de 2011. http://www. edge.org/3rd_culture/haidt11/haidt11_index.html [a]

Greenwald, A. G. \& L. H. Krieger. 2006. "Implicit bias: Scientific foundations". California Law Review 94 (4): 945-67. [a]

Gross, N. \& S. Simmons. 2007. "The social and political views of American professors". Working paper presentado en Harvard University Symposium on Professors and Their Politics. 6 de octubre. [a]

Gross, N. 2013. Why are professors liberal and why do conservatives care? Harvard University Press. [a]

Haidt, J. 2001. "The emotional dog and its rational tail: A social intuitionist approach to moral judgment". Psychological Review 108 (4): 814-34. [a]

—. 2011. "The bright future of post-partisan social psychology". Charla dada en la reunión anual de la Society for Personality and Social Psychology, San Antonio, Texas, 27 de enero. http://people.stern.nyu.edu/jhaidt/postpartisan. $\underline{\mathrm{html}}[\mathrm{a}]$

- 2012. The righteous mind: Why good people are divided by politics and religion. Pantheon Books. [a]

Hall, J. A. \& J. D. Carter. 1999. "Gender-stereotype accuracy as an individual difference". Journal of Personality and Social Psychology 77: 350-59. http:// dx.doi.org/10.1037/0022-3514.77.2.350. [AHE]

Hardin, C. D. \& E. T. Higgins. 1996. "Shared reality: How social verification makes the subjective objective". En Handbook of motivation and cognition, volumen 3: The interpersonal context, editado por R. M. Sorrentino \& E. Higgins, 28-84. Guilford Press. [a]

Hardin, G. 1968. "The tragedy of the commons". Science 162 (3859): 1243-8. [JACE] 
Hart, W., D. Albarracín, A. H. Eagly, I. Brechan, M. J. Lindberg \& L. Merrill. 2009. "Feeling validated versus being correct: A meta-analysis of selective exposure to information". Psychological Bulletin 135: 555-88. http:// dx.doi. org/10.1037/a0015701. [AHE]

Heaven, P. C., J. Ciarrochi \& P. Leeson. 2011. "Cognitive ability, right-wing authoritarianism, and social dominance orientation: A five-year longitudinal study amongst adolescents". Intelligence 39 (1): 15-21. [a]

Hewstone, M. E. \& R. E. Brown. 1986. Contact and conflict in intergroup encounters. Basil Blackwell. [JACE]

Hibbing, J. R., K. B. Smith \& J. R. Alford. 2014. "Differences in negativity bias underlie variations in political ideology". Behavioral and Brain Sciences 37 (3): 297-350. [a]

Hodson, G. \& M. A. Busseri. 2012. "Bright minds and dark attitudes: Lower cognitive ability predicts greater prejudice through right-wing ideology and low intergroup contact". Psychological Science 23 (2): 187-95. [a]

Inbar, Y. \& J. Lammers. 2012. "Political diversity in social and personality psychology". Perspectives on Psychological Science 7 (5): 496-503. [a, JACE, RN]

Ioannidis, J. P. 2012. "Why science is not necessarily self-correcting". Perspectives on Psychological Science 7 (6): 645-54. [a]

Iyer, R., S. Koleva, J. Graham, P. Ditto \& J. Haidt. 2012. "Understanding libertarian morality: The psychological dispositions of self-identified libertarians". PLoS ONE 7 (8): e42366. doi:10.1371/journal.pone.0042366. [a]

Janis, I. L. 1972. Victims of groupthink: A psychological study of foreign-policy decisions and fiascoes. Houghton Mifflin. [a]

John, L. K., G. Lowenstein \& D. Prelec. 2012. "Measuring the prevalence of questionable research practices with incentives for truth telling". Psychological Science 23: 524-32. [a]

Jost, J. T. \& M. R. Banaji. 1994. "The role of stereotyping in system-justification and the production of false consciousness". British Journal of Social Psychology 33 (1): 1-27. [a]

Jost, J. T., J. Glaser, A. W. Kruglanski \& F. J. Sulloway. 2003. "Political conservatism as motivated social cognition". Psychological Bulletin 129 (3): 339-75. 10.1037/0033-2909.129.3.339. [a, AHE]

Jussim, L. 2012a. "Liberal privilege in academic psychology and the social sciences", comentario a Inbar \& Lammers (2012). Perspectives on Psychological Science 7 (5): 504-7. [JACE]

- 2012b. Social perception and social reality: Why accuracy dominates bias and self-fulfilling prophecy. Oxford University Press. [a]

Kahan, D. M., H. Jenkins-Smith \& D. Braham. 2011. "Cultural cognition of scientific consensus". Journal of Risk Research 14 (2): 147-74. [a]

Kang, J. \& M. R. Banaji. 2006. "Fair measures: A behavioral realist revision of 'affirmative action'”. California Law Review 94 (4): 1063-118. [a] 
Kemmelmeier, M. 2008. "Is there a relationship between political orientation and cognitive ability? A test of three hypotheses in two studies". Personality and Individual Differences 45: 767-72. [a]

Klein, D. B. 2011. "I was wrong and so are you". The Atlantic, diciembre. http:// www.theatlantic.com/magazine/archive/2011/12/i-was-wrong-and-so-areyou/308713/. [a]

Klein, D. B. \& C. Stern. 2005. "Professors and their politics. The policy views of social scientists". Critical Review 17 (3-4): 257-303. [a]

— 2009. "By the numbers: The ideological profile of professors". En The politically correct university: Problems, scope, and reforms, editado por R. Maranto, R. E. Redding \& F. M. Hess, 15-33. AEI Press. [a]

Koenig, A. M. \& A. H. Eagly. 2014. "Evidence for the social role theory of stereotype content: Observations of groups' roles shape stereotypes". Journal of Personality and Social Psychology 107: 371-92. http://dx.doi.org/10.1037/ a0037215. [AHE]

König, T., M. Marbach \& M. Osnabrügge. 2013. "Estimating party positions across countries and time - A dynamic latent variable model for manifesto data". Political Analysis 21: 468-91. [BEH]

Lamm, H. \& D. G. Myers. 1978. "Group-induced polarization of attitudes and behavior". Advances in Experimental Social Psychology 11: 145-95. [a]

Levendusky, M. 2009. The partisan sort: How liberals became Democrats and conservatives became Republicans. University of Chicago Press. [a]

Lilienfeld, S. O., R. Ammirati \& K. Landfield. 2009. "Giving debiasing away: Can psychological research on correcting cognitive errors promote human welfare?" Perspectives on Psychological Science 4 (4): 390-98. [a]

Lindner, N. M. \& B. A. Nosek. 2009. "Alienable speech: Ideological variations in the application of free-speech principles". Political Psychology 30 (1): 6792. [a]

Lippman, W. 1922. Public opinion. Harcourt, Brace. [LR]

Lowe, W., K. Benoit, S. Mikhaylov \& M. Laver. 2011. "Scaling policy preferences from coded political texts". Legislative Studies Quarterly 36: 123-55. [BEH]

MacCoun, R. J. 1998. "Biases in the interpretation and use of research results". Annual Review of Psychology 49 (1): 259-87. doi:10.1146/annurev. psych.49.1.259. [a]

Mannix, E. \& M. A. Neale. 2005. "What differences make a difference?" Psychological Science in the Public Interest 6: 31-55. [a]

McCauley, C. \& C. L. Stitt. 1978. "An individual and quantitative measure of stereotypes". Journal of Personality and Social Psychology 36: 929-40. [a]

McClintock, C. G., C. B. Spaulding \& H. A. Turner. 1965. "Political orientation of academically affiliated psychologists". American Psychologist 20: 211-21. [a]

McCrae, R. R. 1996. "Social consequences of experiential openness". Psychological Bulletin 120: 323-37. [a] 
Mellers, B., Hertwig, R. \& D. Kahneman. 2001. "Do frequency representations eliminate conjunction effects? An exercise in adversarial collaboration". Psychological Science 12 (4): 269-75. [a]

Menz, M. 2012. "Functional top management team members: A review, synthesis, and research agenda". Journal of Management 38 (1): 45-80. [a]

Mercier, H. \& D. Sperber. 2011. "Why do humans reason? Arguments for an argumentative theory". Behavioral and Brain Sciences 34 (2): 57-74. [a]

Merton, R. K. (1942) 1973. "The normative structure of science”. En The sociology of science: Theoretical and empirical investigations, editado por R. K. Merton, 223-280. University of Chicago Press. [a]

Messick, D. M. \& M. B. Brewer. 1983. "Solving social dilemmas: A review". Review of Personality and Social Psychology 4: 11-44. [JACE]

Mill, J. S. (1859) 1989. On liberty. Cambridge University Press. [a]

Mooney, C. 2012. "Conservatism makes you happy". Salon, 16 de julio. http:// www.salon.com/2012/07/16/conservatism_makes_you_happy/. [a]

Moreno, J. D. 2011. "The body politic: An introduction". Theoretical and Applied Ethics 1 (2): 13-22. [a]

Morgan, G. S., E. Mullen \& L. J. Skitka. 2010. "When values and attributions collide: Liberals' and conservatives' values motivate attributions for alleged misdeeds". Personality and Social Psychology Bulletin 36: 1241-54. [a]

Moscovici, S. \& B. Personnaz. 1980. "Studies in social influence: V. Minority influence and conversion behavior in a perceptual task". Journal of Experimental Social Psychology 16 (3): 270-82. [a]

Munro, G. D., T. P. Lasane \& S. P. Leary. 2010. "Political partisan prejudice: Selective distortion and weighting of evaluative categories in college admissions applications". Journal of Applied Social Psychology 40 (9): 2434 62. [a]

Napier, J. L. \& J. T. Jost. 2008. "Why are conservatives happier than liberals?" Psychological Science 19 (6): 565-72. [a]

Nemeth, C. J. 1995. "Dissent as driving cognition, attitudes, and judgments". Social Cognition 13 (3): 273-91. [a]

Nemeth, C., K. Brown \& J. Rogers. 2001. "Devil's advocate versus authentic dissent: Stimulating quantity and quality". European Journal of Social Psychology 31 (6): 707-20. [a]

Newcomb, T. 1943. Personality and social change: Attitude formation in a student community. Dryden. [a]

Nickerson, R. S. 1998. "Confirmation bias: A ubiquitous phenomenon in many guises". Review of General Psychology 2 (2): 175-220. [a]

Oxley, D. R., K. B. Smith, J. R. Alford, M. V. Hibbing, J. L. Miller, M. Scalora, P. K. Hatemi \& J. R. Hibbing. 2008. "Political attitudes vary with physiological traits". Science 321 (5896): 1667-70. [a]

Page, S. E. 2008. The difference: How the power of diversity creates better groups, firms, school, and societies. Princeton University Press. [a] 
Perkins, D. N., Farady, M. \& B. Bushey. 1991. "Everyday reasoning and the roots of intelligence". En Informal reasoning and education, editado por D. N. Perkins, M. Farady \& B. Bushey, 83-105. Erlbaum. [a]

Peterson, B. E., L. E. Duncan \& J. S. Pang. 2002. "Authoritarianism and political impoverishment: Deficits in knowledge and civic disinterest". Political Psychology 23 (1): 97-112. [a]

Pettigrew, T. F. \& L. R. Tropp. 2006. "A meta-analytic test of intergroup contact theory". Journal of Personality and Social Psychology 90 (5): 751-83. [JACE]

Pinker, S. 2002. The blank slate: The modern denial of human nature. Viking. [SP]

—. 2005. "Sex ed: The science of difference". The New Republic, 14 de febrero, 15-17. [SP]

— 2011. The better angels of our nature: Why violence has declined. Viking. [SP]

Pinker, Susan. 2008. The sexual paradox: Men, women, and the real gender gap. Scribner. [a, SP]

Popper, K. R. 1959. The logic of scientific discovery. Hutchinson. [a]

- 1968. The open society. Routledge. [a]

Pronin, E., D. Y. Lin \& L. Ross. 2002. "The bias blind spot: Perceptions of bias in self versus others". Personality and Social Psychology Bulletin 28 (3): 36981. [a]

Redding, R. E. 2001. "Sociopolitical diversity in psychology: The case for pluralism". American Psychologist 56 (3): 205-15. [a]

—. 2013. "Politicized science". Society 50: 439-46. [a]

Reskin, B. 2012. "The race discrimination system". Annual Review of Sociology 38: 17-35. [a]

Ridley, M. 2010. The rational optimist: How prosperity evolves. Harper Collins. [SP]

Roets, A. \& A. van Hiel. 2011. "Allport's prejudiced personality today: Need for closure as the motivated cognitive basis of prejudice". Current Directions in Psychological Science 20 (6): 349-54. [a]

Rothman, S. \& S. R. Lichter. 2008. "The vanishing conservative: Is there a glass ceiling?" En The politically correct university: Problems, scope, and reforms, editado por R. Maranto, R. E. Redding \& F. M. Hess, 60-76. AEI Press. [a]

Rothman, S., S. R. Lichter \& N. Nevitte. 2005. "Politics and professional advancement”. Academic Questions 18 (2): 71-84. doi:10.1007/s12129-005-1008-y (originalmente publicado en The Forum. http://www.bepress.com/forum/vol3/ iss1/art2/). [a]

Rudman, L. A., C. A. Moss-Racusin, J. E. Phelan \& S. Nauts. 2012. "Status incongruity and backlash effects: Defending the gender hierarchy motivates prejudice against female leaders". Journal of Experimental Social Psychology 48: 165-79. http://dx.doi.org/10.1016/j.jesp.2011.10.008. [AHE]

Ryan, C. S. 2003. "Stereotype accuracy". En European Review of Social Psychology, volumen 13, editado por W. Stroebe \& M. Hewstone, 
75-109. Psychology Press/Taylor \& Francis (UK). http://dx.doi. org/10.1080/10463280240000037. [a, AHE]

Saad, L. 2010. "In 2010 conservatives still outnumber moderates, liberals". Gallup Politics, 25 de junio. http://www.gallup.com/poll/141032/2010Conservatives-Outnumber-Moderates-Liberals.aspx. [a]

Sabin, P. 2013. The bet: Paul Ehrlich, Julian Simon, and our gamble over Earth's future. Yale University Press. [a]

Simmons, J. P., L. D. Nelson \& U. Simonsohn. 2011. "False-positive psychology: Undisclosed flexibility in data collection and analysis allows presenting anything as significant”. Psychological Science 22 (11): 1359-66. [a]

Smith, C. (ed.) 2003. The secular revolution: Power, interests, and conflict in the secularization of American public life. University of California Press. [a]

Sniderman, P. M. \& P. E. Tetlock. 1986. "Symbolic racism: Problems of motive attribution in political analysis". Journal of Social Issues 42: 129-50. [a]

Son Hing, L. S., D. R. Bobocel \& M. P. Zanna. 2002. "Meritocracy and opposition to affirmative action: Making concessions in the face of discrimination". Journal of Personality and Social Psychology 83 (3): 493-509. [a]

Son Hing, L. S., D. R. Bobocel, M. P. Zanna \& M. V. McBride. 2007. "Authoritarian dynamics and unethical decision making: High social dominance orientation leaders and high right-wing authoritarianism followers". Journal of Personality and Social Psychology 92 (1): 67-81. [a]

Sperber, D., F. Clément, C. Heintz, O. Mascaro, H. Mercier, G. Origgi \& D. Wilson. 2010. "Epistemic vigilance". Mind and Language 25 (4): 359-93. [a]

Steele, C. M. \& J. Aronson. 1995. "Stereotype threat and the intellectual test performance of African Americans". Journal of Personality and Social Psychology 69: 797-811. http://dx.doi.org/10.1037/0022-3514.69.5.797. [AHE]

Stenner, K. 2009. "Three kinds of conservatism". Psychological Inquiry 20: 14259. [a]

Tetlock, P. E. 1983. "Cognitive style and political ideology”. Journal of Personality and Social Psychology 45: 118-26. [a]

- 1994. "Political psychology or politicized psychology: Is the road to scientific hell paved with good moral intentions?" Political Psychology 15 (3): 509-29. [a]

- 2007. "Diversity paradoxes: Review of Scott Page's "The difference: How the power of diversity creates better groups, firms, schools, and societies". Science 316: 984. [a]

Tetlock, P. E. \& G. Mitchell. 1993. "Liberal and conservative approaches to justice: Conflicting psychological portraits". En Psychological perspectives on justice, editado por B. Mellers \& J. Baron, 234-56. Cambridge University Press. [a]

—. 2009. "Implicit bias and accountability systems: What must organizations do to prevent discrimination?" Research in Organizational Behavior 29: 3-38. [a]

Triandis, H. C., E. R. Hall \& R. B. Ewen. 1965. "Member heterogeneity and dyadic creativity". Human Relations 18 (1): 33-55. [a] 
Tuschman, A. 2013. Inside the conservative brain: What explains their wiring? Salon, 15 de septiembre. http:// www.salon.com/2013/09/15/inside_the_ conservative_brain_what_explains_- their_wiring/. [a]

Van Hiel, A., M. Pandelaere \& B. Duriez. 2004. "The impact of need for closure on conservative beliefs and racism: Differential mediation by authoritarian submission and authoritarian dominance". Personality and Social Psychology Bulletin 30 (7): 824-37. [a]

Walton, G. M. 2014. "The new science of wise psychological interventions". Current Directions in Psychological Science 23: 73-82. [LR]

Walton, G. M. \& G. L. Cohen. 2011. "A brief social belonging intervention improves academic and health outcomes of minority students". Science 331: 1447-51. [LR]

Weaver, D., R. Beam, B. Brownlee, P. S. Voakes \& G. C. Wilhoit. 2003. The American journalist survey. Indiana University School of Journalism. [AG]

Wetherell, G. A., M. J. Brandt \& C. Reyna. 2013. "Discrimination across the ideological divide: The role of value violations and abstract values in discrimination by liberals and conservatives". Social Psychology and Personality Science 4 (6): 658-67. [a]

Williams, K. Y. \& C. A. O'Reilly. 1998. "Demography and diversity in organizations: A review of 40 years of research". Research in Organizational Behavior 20: 77-140. [a]

Woessner, M. \& A. Kelly-Woessner. 2009. "Left pipeline: Why conservatives don't get doctorates". En The politically correct university: Problems, scope, and reforms, editado por R. Maranto, R. E. Redding \& F. M. Hess, 38-59. American Enterprise Institute/AEI Press. [a]

Wood, W. \& A. H. Eagly. 2012. "Biosocial construction of sex differences and similarities in behavior". En Advances in Experimental Social Psychology, volumen 46, editado por J. M. Olson \& M. P. Zanna, 55-123. Elsevier/ Academic Press. http://dx.doi.org/10.1016/B978-0-12-394281-4.00002-7. [AHE]

Zimbardo, P. G. 2004. "Does psychology make a significant difference in our lives?" American Psychologist 59: 339-51. [a]

Zipp, J. F. \& R. Fenwick. 2006. "Is the academy a liberal hegemony? The political orientations and educational values of professors". Public Opinion Quarterly 70 (3): 30-326. [a] EP 